\title{
Comparison of Measurement and Electromagnetic Overall Transfer Matrix Simulation Results of MgF 2 -Nb 205 Distributed Bragg Reflectors with Different Layers
}

\author{
Hsien-Wei Tseng \\ Yango University \\ Bo-Syuan. Chen \\ National Chi Nan University \\ You-Lin Wu \\ National Chi Nan University \\ Jing-Jenn Lin \\ National Chi Nan University \\ Cheng-Fu Yang ( $\sim$ cfyang@nuk.edu.tw ) \\ National University of Kaohsiung
}

\section{Research Article}

Keywords: MgF2-Nb2O5 bilayer film, Sheppard's approximate equation, Overall transfer matrix

Posted Date: May 12th, 2021

DOl: https://doi.org/10.21203/rs.3.rs-514602/v1

License: (c) (i) This work is licensed under a Creative Commons Attribution 4.0 International License.

Read Full License 


\title{
Comparison of Measurement and Electromagnetic Overall Transfer Matrix Simulation Results of $\mathrm{MgF}_{2}-\mathrm{Nb}_{2} \mathrm{O}_{5}$ Distributed Bragg Reflectors with Different Layers
}

\author{
Hsien-Wei Tseng ${ }^{1}$, Bo-Syuan Chen², You-Lin Wu ${ }^{3}$, Jing-Jenn Lin ${ }^{2 *}$, Cheng-Fu Yang ${ }^{4,5 *}$ \\ ${ }^{1}$ College of Artificial Intelligence, Yango University, Mawei District, Fujian, China 350015; \\ hsienwei.tseng@gmail.com \\ ${ }^{2}$ Department of Applied Materials and Optoelectronic Engineering, National Chi Nan University; \\ s106328503@ncnu.edu.tw (B.S. Chen); cclin@ncnu.edu.tw (J.J. Lin) \\ ${ }^{3}$ Department of Electrical Engineering, National Chi Nan University, Taiwan; \\ ylwu@ncnu.edu.tw (Y.L. Wu) \\ ${ }^{4}$ Department of Chemical and Materials Engineering, National University of Kaohsiung, Kaohsiung \\ 811, Taiwan; cfyang@nuk.edu.tw (C.F. Yang) \\ ${ }^{5}$ Department of Aeronautical Engineering, Chaoyang University of Technology, Taichung 413,
} Taiwan

*Corresponding author: cclin@ncnu.edu.tw (J.J. Lin); cfyang@nuk.edu.tw (C.F. Yang)

In this study, glasses were used as substrates and an e-beam was used the method to deposit $\mathrm{MgF}_{2}$ and $\mathrm{Nb}_{2} \mathrm{O}_{5}$ single-layer films, and the optical properties, including extinction coefficients (k values) and refractive indices (n values), were measured by using the light wavelength as variable. The equation $d=\lambda /(4 \mathrm{n})$ was used to calculate the thickness $(\mathrm{d})$ of $1 / 4$ wavelength $(\lambda)$ for each layer of the $\mathrm{MgF}_{2}-\mathrm{Nb}_{2} \mathrm{O}_{5}$ bilayer films in distributed Bragg reflectors (DBRs) with a designed reflective wavelength at blue light ( $450 \mathrm{~nm})$. Each $\mathrm{MgF}_{2}-\mathrm{Nb}_{2} \mathrm{O}_{5}$ bilayer film was called a period, and the glass substrates were used to deposit the films with two, four, and six periods for fabricating the DBRs. The field emission scanning electron microscope equipped with a focused ion beam was used to measure the thickness of each $\mathrm{MgF}_{2}-\mathrm{Nb}_{2} \mathrm{O}_{5}$ layer in the DBRs with different periods. The measured maximum reflective ratios were compared with Sheppard's approximate equation, which calculates 
only the maximum reflective ratio at a specific wavelength. An overall transfer matrix was investigated to calculate the reflective spectra by incorporating the variable $\mathrm{n}$ values and thicknesses of the $\mathrm{MgF}_{2}-\mathrm{Nb}_{2} \mathrm{O}_{5}$ films in each layer. We show that the measured results of the fabricated DBRs matched the results simulated using Sheppard's approximate equation and the overall transfer matrix. Keywords: $\mathrm{MgF}_{2}-\mathrm{Nb}_{2} \mathrm{O}_{5}$ bilayer film; Sheppard's approximate equation; Overall transfer matrix

\section{Introduction}

Multilayer films are composite films deposited using numbers of alternating layers of different materials (for example, metal oxides), these films have their specific thicknesses as they are with nanometer scale. Multilayer films with different materials have been widely used in a large number of applications because they have outstanding optical, photoactive, and protective properties. For example, to achieve a long lifetime for semiconductive lasers with a microcavity exciton-polariton, it is necessary to use a highly reflective distributed Bragg reflector (DBR) $)^{1,2}$. A DBR is a reflector designed for a specific wavelength with a narrow bandwidth, which can be used to design a notch filter $^{3}$. DBRs are also used in waveguides, and they can be constructed from multiple layers of different materials with periodic variations in refractive indices (n values, materials with low and high $\mathrm{n}$ values are alternately stacked in the vertical direction), and these films have a quarter-wave $(\lambda / 4)$ thickness of the designed reflective wavelength. Bilayer film designs can be found in commercial wavelength division multiplexers, which have single-period structures of $\mathrm{H}\left(\mathrm{Ta}_{2} \mathrm{O}_{5}\right) / \mathrm{L}\left(\mathrm{SiO}_{2}\right)$, $\mathrm{H}\left(\mathrm{Nb}_{2} \mathrm{O}_{5}\right) / \mathrm{L}\left(\mathrm{SiO}_{2}\right), \mathrm{H}\left(\mathrm{TiO}_{2}\right) / \mathrm{L}\left(\mathrm{SiO}_{2}\right)$, or $\mathrm{H}\left(\mathrm{TiO}_{2}\right) / \mathrm{L}\left(\mathrm{Al}_{2} \mathrm{O}_{3}\right)$ and use different numbers of periods ${ }^{4-6}$.

Many materials have been used to form the periodically varying layers, including organic polymers and inorganic oxides ${ }^{7}$. Guldin et al. investigated a fast and versatile route to fabricate mesoporous DBRs. They used the self-assembling isoprene-block-ethylene oxide (PI-b-PEO) in two stack solutions containing $\mathrm{PI}-b$-PEO copolymer and $\mathrm{TiO}_{2}$ sol with different weight ratios to sequentially spin-cast layers, forming stacks of alternating compositions ${ }^{8}$. Many deposition technologies have been investigated to deposit films with specific requirements or properties. For example, Lin et al. used a spin-coating and annealing technique to deposit $\mathrm{PbZr}_{0.4} \mathrm{Ti}_{0.6} \mathrm{O}_{3}$ multilayer 
films ${ }^{9}$, and Wang et al. used a $\mathrm{CO}_{2}$ laser to fabricate $\mathrm{SiO}_{2}-\mathrm{Al}_{2} \mathrm{O}_{3}$ glasses with a thermally stable $\mathrm{n}$ value ${ }^{10}$. Dubey and Ganesan used a sol-gel spin-coating technique to fabricate DBRs based on $\mathrm{TiO}_{2}$ $\mathrm{SiO}_{2}$ stacks, but as the $\mathrm{TiO}_{2}-\mathrm{SiO}_{2}$ films were deposited in seven periods, only about $90 \%$ reflectance was observed $^{11}$. Muallem et al. used a thermal evaporation method to fabricate multilayer DBRs using $\mathrm{CaF}_{2}$ as material with lower $\mathrm{n}$ value and $\mathrm{ZnS}$ as material with higher $\mathrm{n}$ value, and they found that the fabricated DBRs exhibited a center wavelength of 550nm with a maximum reflectance more than $99 \%{ }^{12}$.

Willey and Shakoury used ion beam-assisted deposition to deposit an $\mathrm{MgF}_{2}$ film without additional heat or fluorine, and the deposited film exhibited low absorbance, low scattering, and a low $\mathrm{n}$ value ${ }^{13}$. Chen et al. used a sputtering method to deposit $\mathrm{Nb}_{2} \mathrm{O}_{5}$ films under different oxygen concentrations and found that when they introduced oxygen during the deposition process, the deposited $\mathrm{Nb}_{2} \mathrm{O}_{5}$ film had low absorbance and a high $\mathrm{n}$ value ${ }^{14}$. In the present study, we used the $\mathrm{MgF}_{2}$ and $\mathrm{Nb}_{2} \mathrm{O}_{5}$ films as low and high refractive-index films to fabricate a DBR with a centrally reflective frequency of $450 \mathrm{~nm}$. An electron-beam (e-beam) deposition can be a simple method to deposit the different oxide films, and the properties of the deposited films depend on the deposition parameters, such as temperature and pressure, and the used gas during deposition ${ }^{5,6,14}$. The e-beam deposition method makes it easy to control the thicknesses of the films, even in multilayer structures or special structures, so the e-beam technology was used for deposition the $\mathrm{MgF}_{2}-\mathrm{Nb}_{2} \mathrm{O}_{5}$ bilayer films.

In the past, $\mathrm{Du}$ et al. also used bi-layer $\mathrm{MgF}_{2}$ and $\mathrm{Nb}_{2} \mathrm{O}_{5}$ films to design a $500 \mathrm{~nm} \mathrm{DBR}$, but they only used the e-beam to deposit the bi-layer $\mathrm{MgF}_{2}$ and $\mathrm{Nb}_{2} \mathrm{O}_{5}$ films and investigated their properties ${ }^{15}$. In this study, we would investigate a transfer matrix to find the difference between the simulated and measured results of the fabricated DBRs. The variations in the reflective ratios of multilayer $\mathrm{MgF}_{2}-$ $\mathrm{Nb}_{2} \mathrm{O}_{5}$ DBRs versus the variations in period numbers is simulated using Sheppard's approximate equation ${ }^{16}$ :

$$
\mathrm{R}=\left[\frac{\left(\mathrm{n}_{\mathrm{H}}\right)^{2 \mathrm{P}}-\left(\mathrm{n}_{0} / \mathrm{n}_{\mathrm{s}}\right) \times\left(\mathrm{n}_{\mathrm{L}}\right)^{2 \mathrm{P}}}{\left(\mathrm{n}_{\mathrm{H}}\right)^{2 \mathrm{P}}+\left(\mathrm{n}_{0} / \mathrm{n}_{\mathrm{s}}\right) \times\left(\mathrm{n}_{\mathrm{L}}\right)^{2 \mathrm{P}}}\right]^{2}
$$

where $\mathrm{n}_{\mathrm{L}}, \mathrm{n}_{\mathrm{H}}, \mathrm{n}_{\mathrm{S}}$, and $\mathrm{n}_{0}$ are $\mathrm{MgF}_{2}\left(\mathrm{n}_{\mathrm{L}}=1.39\right), \mathrm{Nb}_{2} \mathrm{O}_{5}\left(\mathrm{n}_{\mathrm{H}}=2.29\right)$, glass substrate $\left(\mathrm{n}_{\mathrm{S}}=1.52\right)$, and air 
$\left(\mathrm{n}_{0}=1\right), \mathrm{R}$ represents the reflective ratio at a special wavelength of light, and $\mathrm{P}$ is the deposited period of the $\mathrm{MgF}_{2}-\mathrm{Nb}_{2} \mathrm{O}_{5}$ bilayer films.

If the $\mathrm{n}$ values of the two films differ greatly, the fabricated DBR will have a similar reflective ratio if fewer periods are deposited, or a higher reflective ratio if the designed device has the same number of periods. Knowing this saves time and money when designing DBRs, due to the $\mathrm{n}$ values of the $\mathrm{MgF}_{2}\left(\mathrm{n}_{\mathrm{L}}=1.39\right)$ and $\mathrm{Nb}_{2} \mathrm{O}_{5}$ films $\left(\mathrm{n}_{\mathrm{H}}=2.29\right) . \mathrm{MgF}_{2}$ and $\mathrm{Nb}_{2} \mathrm{O}_{5}$ films have low extinction coefficients ( $\mathrm{k}$ values), as well as high transparent ratios in the near-infrared, visible, and ultraviolet regions. In optical applications, $\mathrm{Nb}_{2} \mathrm{O}_{5}$ film can be used as a low-loss and high-index material, and $\mathrm{MgF}_{2}$ film can be used as a low-loss and low-index material. There are two reasons for us to use $\mathrm{MgF}_{2}$ and $\mathrm{Nb}_{2} \mathrm{O}_{5}$ films to design reflective films having a multi-period $\mathrm{L}\left(\mathrm{MgF}_{2}, 1 / 4 \lambda\right) / \mathrm{H}\left(\mathrm{Nb}_{2} \mathrm{O}_{5}, 1 / 4 \lambda\right)$ bilayer structure. The first is that the $\mathrm{MgF}_{2}$ film $(\mathrm{n} \sim 1.39 \text { in light range of } 400 \sim 700 \mathrm{~nm})^{17}$ and the $\mathrm{Nb}_{2} \mathrm{O}_{5}$ film $(\mathrm{n} \sim 2.30 \text { in visible light })^{14}$ have very different $\mathrm{n}$ values. The second is that both materials have low $\mathrm{k}$ values ${ }^{14,17}$. In this paper, we show that even with only four periods of the $\mathrm{MgF}_{2}-\mathrm{Nb}_{2} \mathrm{O}_{5}$ bilayer films deposited, the fabricated DBRs had a reflective ratio of over $90 \%$.

However, Equation (1) is only used to simulate the maximum reflective ratio at a designed wavelength, and it cannot simulate the reflective spectrum in a very wide range of light wavelength. In this study, we investigated the transfer matrix of each layer and obtained an overall transfer matrix of the multilayer coatings, which is formed using the product of each single transfer matrix. The following steps were carried out for investigating the potential difference between the experimental measurements and simulation estimations for an $\mathrm{MgF}_{2}-\mathrm{Nb}_{2} \mathrm{O}_{5}$ bilayer blue-light Bragg reflector with different periods. First, we deposited single-layer $\mathrm{MgF}_{2}$ and $\mathrm{Nb}_{2} \mathrm{O}_{5}$ films on glass substrates, their $\mathrm{k}$ values and $n$ values were measured, and the thicknesses to match the $\lambda / 4 \mathrm{MgF}_{2}$ and $\mathrm{Nb}_{2} \mathrm{O}_{5}$ films could be obtained. Next, a characteristic matrix for simulating the multilayer films was constructed to calculate the reflective spectra of a bilayer $\mathrm{MgF}_{2}-\mathrm{Nb}_{2} \mathrm{O}_{5}$ Bragg reflector with different periods by using the optical properties of the single-layer $\mathrm{MgF}_{2}$ and $\mathrm{Nb}_{2} \mathrm{O}_{5}$ films. Third, we deposited bilayer $\mathrm{MgF}_{2}-\mathrm{Nb}_{2} \mathrm{O}_{5}$ DBRs according to the calculated thicknesses of the $\lambda / 4 \mathrm{MgF}_{2}$ and $\mathrm{Nb}_{2} \mathrm{O}_{5}$ films, then measured the reflective spectra of the fabricated DBRs. In what follows, we provide a detailed 
comparison of the experimental and theoretical results for the multilayer blue-light $\mathrm{MgF}_{2}-\mathrm{Nb}_{2} \mathrm{O}_{5}$ DBRs and discuss reasons for deviations between the measured and simulated results.

\section{Experimental Procedure}

Corning 1737 glass substrates (the area was $2 \times 2 \mathrm{~cm}^{2}$ ) were cleaned, then $\mathrm{MgF}_{2}$ and $\mathrm{Nb}_{2} \mathrm{O}_{5}$ single-layer films were deposited on them using e-beam technology to measure their k values and $\mathrm{n}$ values. The thickness of the Corning 1737 glass was about $2 \mathrm{~mm}$. The deposited $\mathrm{MgF}_{2}$ and $\mathrm{Nb}_{2} \mathrm{O}_{5}$ single-layer films and the $\mathrm{MgF}_{2}-\mathrm{Nb}_{2} \mathrm{O}_{5}$ bilayer films were much thinner than the glass substrates, to prevent the coherent condition that would be caused by multiple light reflections in the substrates. The base chamber pressure to start the deposition was $6 \times 10^{-6}$ Torr, for the electron beam the applied voltage and current were $4 \mathrm{kV}$ and $20 \mathrm{~mA}$, and $25^{\circ} \mathrm{C}$ (room temperature) was used the deposition temperatures of the $\mathrm{MgF}_{2}$ and $\mathrm{Nb}_{2} \mathrm{O}_{5}$ films. The thicknesses of the $\mathrm{MgF}_{2}$ and $\mathrm{Nb}_{2} \mathrm{O}_{5}$ films were 57.7 and $58.4 \mathrm{~nm}$, which were controlled by a film gauge on the e-beam and verified by field-emission scanning electron microscopy (FESEM). When the $\mathrm{MgF}_{2}$ and $\mathrm{Nb}_{2} \mathrm{O}_{5}$ films were deposited at higher temperatures or were annealed, the films' densities increased and/or the average crystallite sizes increased. There were two important reasons for us to deposit the $\mathrm{MgF}_{2}$ and $\mathrm{Nb}_{2} \mathrm{O}_{5}$ films at room temperature. First, as the films' densities increased, their thicknesses decreased and became not easy to control, causing variations in the central wavelength of the reflective band. Second, as the crystallite sizes increased, grain boundaries formed between crystallites of different sizes; this increased the chance of the light scattering, which in turn affected the reflectance and transmittance efficiencies of the multilayer films.

For the deposition of the $\mathrm{MgF}_{2}-\mathrm{Nb}_{2} \mathrm{O}_{5}$ bilayer films, at first an $\mathrm{MgF}_{2}$ film was deposited on a glass substrate, after that a $\mathrm{Nb}_{2} \mathrm{O}_{5}$ film was deposited on the $\mathrm{MgF}_{2}$ film, and then one period of the $\mathrm{MgF}_{2}-\mathrm{Nb}_{2} \mathrm{O}_{5}$ bilayer film was formed, as Figure 1 shows. For the investigation of the effect of period number on the properties of the designed blue-light DBRs, different periods of the $\mathrm{MgF}_{2}-\mathrm{Nb}_{2} \mathrm{O}_{5}$ bilayer films were deposited. The DBRs' center wavelength was 450nm, and the thicknesses of the $\mathrm{MgF}_{2}$ and $\mathrm{Nb}_{2} \mathrm{O}_{5}$ films were 80.9 and $49.0 \mathrm{~nm}$, respectively. The $\mathrm{k}$ values and $\mathrm{n}$ values of the $\mathrm{MgF}_{2}$ 
and $\mathrm{Nb}_{2} \mathrm{O}_{5}$ films were measured along the direction of thickness using a normal light incidence on single-layer films with an n\&k analyzer. The n\&k analyzer was able to measure thickness (d), n value, $\mathrm{k}$ value, transmittance spectrum, and reflectance spectrum, and it used a nonlinear curve-fitting method, which fit the measured results using polynomial terms in linear regression, and these measured data can be retrieved directly. X-ray diffraction (XRD) pattern was used to measure the crystalline structure of the $\mathrm{MgF}_{2}$ and $\mathrm{Nb}_{2} \mathrm{O}_{5}$ single-layer films and the $\mathrm{MgF}_{2}-\mathrm{Nb}_{2} \mathrm{O}_{5}$ bilayer film with different periods. The surface observations of top-layer films for different periods of $\mathrm{MgF}_{2}-\mathrm{Nb}_{2} \mathrm{O}_{5}$ bilayer film were measured using FESEM. For measuring the real thicknesses of each $\mathrm{MgF}_{2}$ and $\mathrm{Nb}_{2} \mathrm{O}_{5}$ film for different periods, we used a focused ion beam to prepare the samples and used the FESEM to observe the cross sections of the $\mathrm{MgF}_{2}-\mathrm{Nb}_{2} \mathrm{O}_{5}$ bilayer films. The $\mathrm{n} \& \mathrm{k}$ analyzer was also used to measure the reflective spectra of the $\mathrm{MgF}_{2}-\mathrm{Nb}_{2} \mathrm{O}_{5}$ bilayer films with different periods in the light wavelength range of 300-800nm.

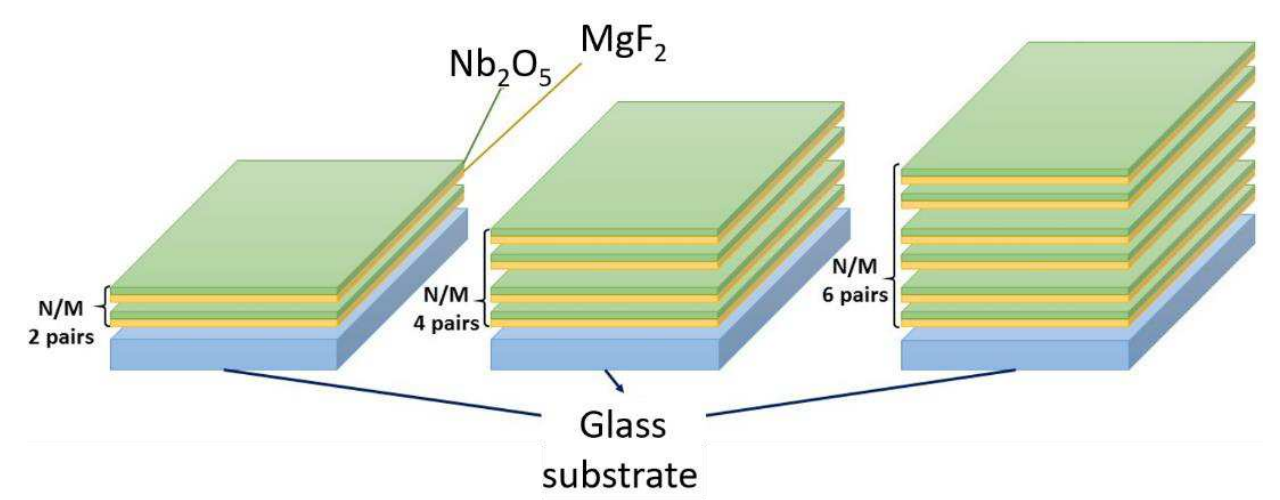

Figure 1. Structure of designed $\mathrm{MgF}_{2}-\mathrm{Nb}_{2} \mathrm{O}_{5}$ bilayer films with different periods.

Light is one kind of electromagnetic wave, for a single-layer film on a substrate (substrate-thin film-air), the interface between substrate and film and that between film and air were denoted by $b$ and a, respectively, and the transmission $(\tau)$ and amplitude reflection $(\rho)$ coefficients were $^{18,19}$ :

$$
\tau=\frac{E_{b}}{E_{0 a}^{+}}=\frac{2 \eta_{0} E_{b}}{\eta_{0} E_{a}+H_{a}} \quad \rho=\frac{E_{0 a}^{-}}{E_{0 a}^{+}}=\frac{\eta_{0} E_{a}-H_{a}}{\eta_{0} E_{a}+H_{a}}
$$

Therefore, the relationship between magnetic field $(H a)$ and electrical field $(E a)$ can be written in matrix equation shown below ${ }^{18,19}$ :

$$
\left[\begin{array}{l}
E_{a} \\
H_{a}
\end{array}\right]=\left[\begin{array}{cc}
\cos \delta & \frac{i}{N} \sin \delta \\
i N \sin \delta & \cos \delta
\end{array}\right]\left[\begin{array}{c}
E_{b} \\
H_{b}
\end{array}\right]
$$


where $\delta$ represents the phase factor and it can be shown below

$$
\delta=2 \pi N \mathrm{~d} \cos (\theta) / \lambda
$$

Where $\mathrm{N}$ is the complex index and it is equal to (nr - ikr), $\mathrm{d}$ is the thickness of the film, $\lambda$ is the wavelength of light, $\mathrm{k}$ is the extinction coefficient, and $\mathrm{n}$ is the refractive index. $N$ is a modified optical admittance of the deposited film and it can be shown as below:

$$
N=\overrightarrow{\mathrm{E}} / \overrightarrow{\mathrm{H}}
$$

For the multilayer films, when light is propagated from the front face of a reference plane (often is the air) to the surfaces of the multilayer films, and then to the substrate, the variation in the input optical admittance can be listed as follows for single-layer, two-layer (one period, $\mathrm{P}=1$ ), four-layer (two periods, $\mathrm{P}=2$ ), eight-layer (four periods, $\mathrm{P}=4$ ), and twelve-layer (six periods, $\mathrm{P}=6$ ) structures:

$$
\begin{aligned}
& {\left[\begin{array}{l}
\mathrm{B}_{1} \\
\mathrm{C}_{1}
\end{array}\right]=\left[\begin{array}{cc}
\cos \delta_{1} & \frac{i}{N} \sin \delta_{1} \\
i N \sin \delta_{1} & \cos \delta_{1}
\end{array}\right]\left[\begin{array}{c}
1 \\
y_{s}
\end{array}\right], \mathrm{Y}_{1}=\frac{B_{1}}{C_{1}}} \\
& {\left[\begin{array}{l}
\mathrm{B}_{2} \\
\mathrm{C}_{2}
\end{array}\right]=\left[\begin{array}{cc}
\cos \delta_{2} & \frac{i}{N} \sin \delta_{2} \\
i N \sin \delta_{2} & \cos \delta_{2}
\end{array}\right]\left[\begin{array}{c}
1 \\
\mathrm{Y}_{1}
\end{array}\right], \mathrm{Y}_{2}=\frac{B_{2}}{C_{2}}} \\
& {\left[\begin{array}{l}
\mathrm{B}_{4} \\
\mathrm{C}_{4}
\end{array}\right]=\left[\begin{array}{cc}
\cos \delta_{4} & \frac{i}{N} \sin \delta_{4} \\
i N \sin \delta_{4} & \cos \delta_{4}
\end{array}\right]\left[\begin{array}{c}
1 \\
\mathrm{Y}_{3}
\end{array}\right], \quad \mathrm{Y}_{4}=\frac{B_{4}}{C_{4}}} \\
& {\left[\begin{array}{l}
\mathrm{B}_{8} \\
\mathrm{C}_{8}
\end{array}\right]=\left[\begin{array}{cc}
\cos \delta_{8} & \frac{i}{N} \sin \delta_{8} \\
i N \sin \delta_{8} & \cos \delta_{8}
\end{array}\right]\left[\begin{array}{c}
1 \\
\mathrm{Y}_{9}
\end{array}\right], \mathrm{Y}_{8}=\frac{B_{8}}{C_{8}}} \\
& {\left[\begin{array}{l}
\mathrm{B}_{12} \\
\mathrm{C}_{12}
\end{array}\right]=\left[\begin{array}{cc}
\cos \delta_{12} & \frac{i}{N} \sin \delta_{12} \\
i N \sin \delta_{12} & \cos \delta_{12}
\end{array}\right]\left[\begin{array}{c}
1 \\
\mathrm{Y}_{11}
\end{array}\right], \mathrm{Y}_{12}=\frac{B_{12}}{C_{12}}} \\
& \mathrm{R}=|\rho|^{2}=\frac{\left|Y_{0}-Y_{4}\right|^{2}}{\left|Y_{0}+Y_{4}\right|^{2}} \text { for } \mathrm{P}=2 \\
& \mathrm{R}=|\rho|^{2}=\frac{\left|Y_{0}-Y_{8}\right|^{2}}{\left|Y_{0}+Y_{8}\right|^{2}} \quad \text { for } \mathrm{P}=4 \\
& \mathrm{R}=|\rho|^{2}=\frac{\left|Y_{0}-Y_{12}\right|^{2}}{\left|Y_{0}+Y_{12}\right|^{2}} \text { for } \mathrm{P}=6
\end{aligned}
$$

where $y_{s}$ is the admittance of the substrate.

\section{Results and Discussion}

At first, we used XRD patterns to measure the crystalline structures of the $\mathrm{MgF}_{2}$ and $\mathrm{Nb}_{2} \mathrm{O}_{5}$ single-layer films and one-period $\mathrm{MgF}_{2}-\mathrm{Nb}_{2} \mathrm{O}_{5}$ bilayer films; the results are shown in Figure 2. No characteristic peaks were found in the XRD patterns, because these films deposited using the e-beam 
process would present in the amorphous phase. We believe that because the e-beam deposition process was carried out at room temperature, the natures of the single-layer and bilayer films remained unchanged. The XRD patterns of $\mathrm{MgF}_{2}-\mathrm{Nb}_{2} \mathrm{O}_{5}$ bilayer films with different periods were also measured (not shown here); again, only the amorphous phase was observed.

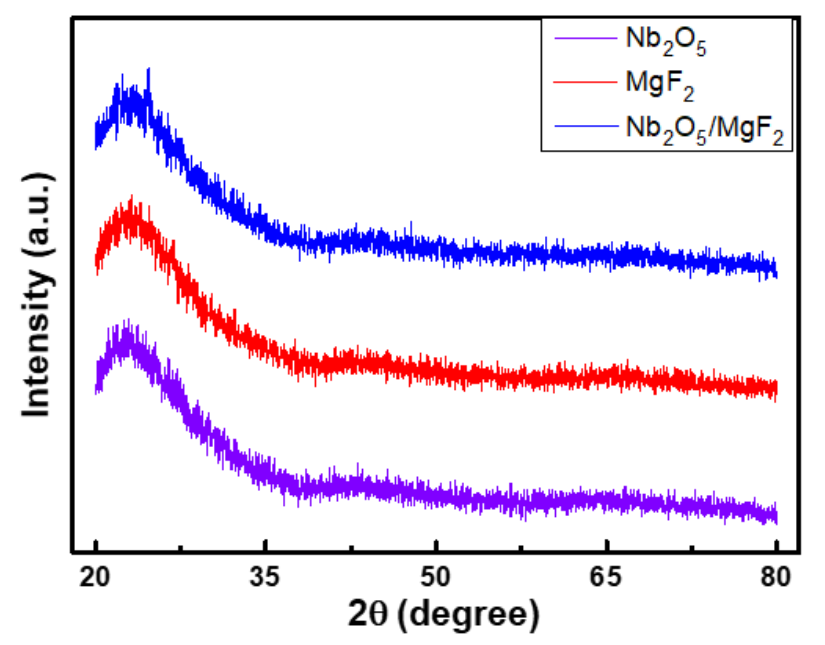

Figure 2. XRD patterns of $\mathrm{MgF}_{2}$ and $\mathrm{Nb}_{2} \mathrm{O}_{5}$ single-layer films and $\mathrm{MgF}_{2}-\mathrm{Nb}_{2} \mathrm{O}_{5}$ bilayer film.

In optics, the $\mathrm{n}$ value of a film or material is a unitless number, which describes how the light or electromagnetic wave propagates into or through the film or material. The $n$ value can be defined as $\mathrm{n}=\mathrm{c} / \mathrm{v}$, where $\mathrm{v}$ is the speed of light in the film or material and $\mathrm{c}$ is the speed of light in a vacuum. The $\mathrm{n}$ value is not a stable value and may change as the incident light changes its wavelength. The $\mathrm{k}$ value, also called the molar extinction coefficient, is a measure of how much a chemical species or material absorbs incident light at a particular wavelength. It is an intrinsic property and is strongly dependent upon the species or material's composition. The $\mathrm{n}$ and $\mathrm{k}$ values are corresponding to the interaction between incident light and a film or material, and the k value is associated with refraction and absorption.

The $\mathrm{n}$ values and $\mathrm{k}$ values of the $\mathrm{MgF}_{2}$ film and glass substrate were measured in the light wavelength range of 200-1700nm. However, the optical properties of the $\mathrm{Nb}_{2} \mathrm{O}_{5}$ film were measured in the light wavelength range of $350-1700 \mathrm{~nm}$, because as the light wavelength was shorter than $350 \mathrm{~nm}$, its $\mathrm{n}$ and $\mathrm{k}$ values increased sharply, and correct values were difficult to obtain. The $\mathrm{n}$ values of the $\mathrm{MgF}_{2}$ and $\mathrm{Nb}_{2} \mathrm{O}_{5}$ films and the glass substrate were measured as a function of light wavelength 
and the results are shown in Figure 3(a). The $\mathrm{Nb}_{2} \mathrm{O}_{5}$ film had an $\mathrm{n}$ value of 2.52 at $350 \mathrm{~nm}$, which decreased sharply as the light wavelength became longer; at 400, 500, and 700nm, the $\mathrm{n}$ values were $2.38,2.23$, and 2.15 , respectively. The $\mathrm{n}$ value of the $\mathrm{Nb}_{2} \mathrm{O}_{5}$ film underwent no apparent change when the light wavelength was longer than $700 \mathrm{~nm}$. The $\mathrm{MgF}_{2}$ film (glass substrate) had an $\mathrm{n}$ value of 1.45 (1.64) at 200nm, the n value decreased slightly as the light wavelength became longer, and at 300 and $400 \mathrm{~nm}$, the $\mathrm{n}$ values were 1.41 (1.55) and 1.40 (1.52). In this case, the $\mathrm{n}$ values of the $\mathrm{MgF}_{2}$ film and glass substrate remained presenting the stable values as the light wavelength increased. Because we wanted to fabricate an optical reflector with a central wavelength of blue light, we chose $\mathrm{n}$ values of 1.39 and 2.29 (both at $450 \mathrm{~nm}$ ) for the $\mathrm{MgF}_{2}$ and $\mathrm{Nb}_{2} \mathrm{O}_{5}$ films, using the equation $\mathrm{d}=\lambda /(4 \mathrm{n})$ to calculate the thicknesses that matched the designed wavelength of quarter wave, where $\mathrm{n}$ is the refractive index, $\lambda$ is the targeted wavelength of $450 \mathrm{~nm}$, and $\mathrm{d}$ is the film thickness. The thicknesses of 80.9 and $49.0 \mathrm{~nm}$ were matched the thicknesses of $\mathrm{MgF}_{2}$ and $\mathrm{Nb}_{2} \mathrm{O}_{5}$ films for the $\lambda / 4$ condition.

Figure 3(b) shows the $\mathrm{k}$ values of the glass substrate and the $\mathrm{Nb}_{2} \mathrm{O}_{5}$ and $\mathrm{MgF}_{2}$ films in a spectrum range of $200-1700 \mathrm{~nm}$. As the light wavelength increased from 200 to $300 \mathrm{~nm}$, the $\mathrm{k}$ value of the glass substrate decreased quickly from $\sim 0.018$ to close to zero. When the light wavelength increased from 350 to $650 \mathrm{~nm}$, the $\mathrm{k}$ value of the $\mathrm{Nb}_{2} \mathrm{O}_{5}$ single-layer film decreased quickly from $\sim 3.6 \%$ to $\sim 1.6 \%$, and the $\mathrm{k}$ value was less than $1 \%$ when the light wavelength was longer than $1200 \mathrm{~nm}$. Previously, Chen et al. used a sputtering method to deposit $\mathrm{Nb}_{2} \mathrm{O}_{5}$ films in different atmospheres ${ }^{14}$. They found that when pure argon was used as the deposition atmosphere, the $\mathrm{Nb}_{2} \mathrm{O}_{5}$ film had a higher $\mathrm{k}$ value; when oxygen was injected with the argon during the deposition, the $\mathrm{Nb}_{2} \mathrm{O}_{5}$ film had a lower $\mathrm{k}$ value, which dropped to zero as the light wavelength was longer than 346-370nm.

This was because when pure argon was used, a small amount of $\mathrm{Nb}_{2} \mathrm{O}_{5}$ decomposed to form $\mathrm{Nb}_{2} \mathrm{O}_{5-\mathrm{x}}$, which had semiconducting characteristics and thus increased the $\mathrm{k}$ value. When oxygen was mixed with the argon, the $\mathrm{Nb}_{2} \mathrm{O}_{5}$ film did not decompose to form the $\mathrm{Nb}_{2} \mathrm{O}_{5-\mathrm{x}}$ and had a lower $\mathrm{k}$ value. Because we deposited the $\mathrm{Nb}_{2} \mathrm{O}_{5}$ film in a high vacuum, we believe that only a small amount of the $\mathrm{Nb}_{2} \mathrm{O}_{5}$ decomposed to form $\mathrm{Nb}_{2} \mathrm{O}_{5-\mathrm{x}}$, creating oxygen vacancies in the film. The oxygen vacancies increased the film's conductivity and absorption, so the $\mathrm{Nb}_{2} \mathrm{O}_{5}\left(\mathrm{Nb}_{2} \mathrm{O}_{5-\mathrm{x}}\right)$ film had semiconducting 
properties and a higher $\mathrm{k}$ value. However, the deposited $\mathrm{MgF}_{2}$ film had a $\mathrm{k}$ value close to zero even when the measured wavelength was $200 \mathrm{~nm}$. This result suggested that the deposited $\mathrm{MgF}_{2}$ film was a stable and lossless dielectric material. The results in Figure 3(b) suggest that the glass substrate and the $\mathrm{Nb}_{2} \mathrm{O}_{5}$ and $\mathrm{MgF}_{2}$ films were low-loss dielectric materials because they had low $\mathrm{k}$ values in the range of visible light, so they could be used to fabricate DBRs with reflective wavelengths in the visible light spectrum.

Cauchy had proposed a transmission equation to express an empirical relationship between the $\mathrm{n}$ value and light wavelength for a transparent film or material ${ }^{20}$. The equation is valid for the region of normal dispersion in the visible wavelength range. The most general form of Cauchy's equation is

$$
n(\lambda)=\mathrm{a}+\mathrm{b} / \lambda^{2}+\mathrm{c} / \lambda^{4}+\ldots
$$

where $n$ is the n value of the used transparent material; $\lambda$ is the measured wavelength; and $a, b, c$, etc. are coefficients, which are used for determining the parameters in the equation for a material to fit the variables of the $n$ values at a measured wavelength. The coefficients are usually quoted for $\lambda$ as the vacuum wavelength in a material, measured in $\mu \mathrm{m}$. Typically, using a three-term form of the equation is sufficient to express a material:

$$
n(\lambda)=\mathrm{a}+\mathrm{b} / \lambda^{2}+\mathrm{c} / \lambda^{4}
$$

For the $\mathrm{MgF}_{2}$ film, the $\mathrm{a}, \mathrm{b}$, and c values are $1.3805820,2.393871610^{-3}\left(\mu \mathrm{m}^{2}\right)$, and $1.6955936 \mathrm{x}$ $10^{-5}\left(\mu \mathrm{m}^{4}\right)$, and for the $\mathrm{Nb}_{2} \mathrm{O}_{5}$ film, the $\mathrm{a}, \mathrm{b}$, and c values are $2.0830535,2.661404310^{-2}\left(\mu \mathrm{m}^{2}\right)$, and $3.2799308 \times 10^{-3}\left(\mu \mathrm{m}^{4}\right)$. Apparently, as Figures 3(c) and 3(d) show, the $\mathrm{n}$ values calculated using Equation (12) match the variations in the $\mathrm{Nb}_{2} \mathrm{O}_{5}$ and $\mathrm{MgF}_{2}$ films with different wavelengths. Those results have proven that the decreases in the $\mathrm{n}$ values of the $\mathrm{Nb}_{2} \mathrm{O}_{5}$ and $\mathrm{MgF}_{2}$ films were caused by their normal dispersion. 

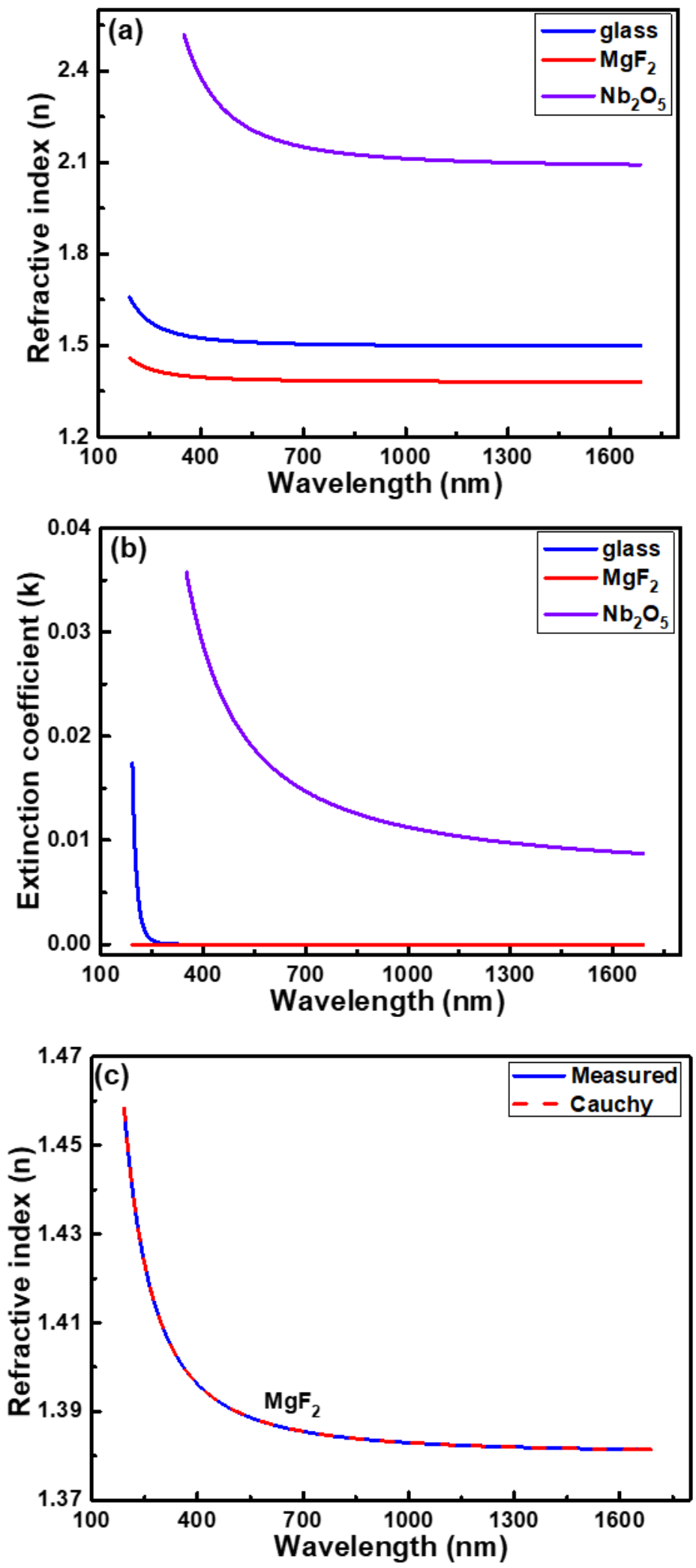


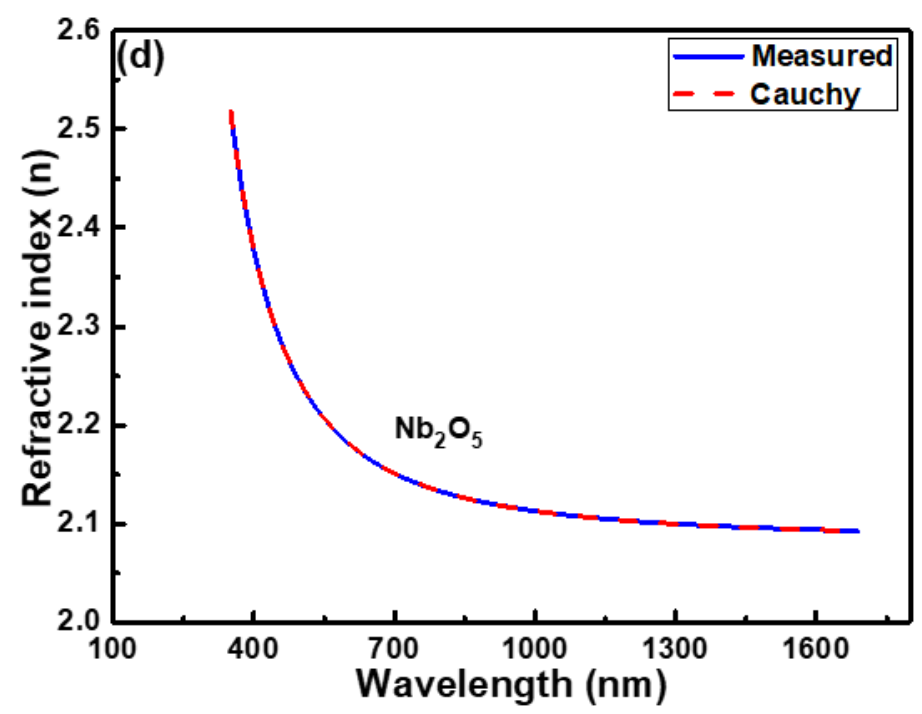

Figure 3. Measured (a) $n$ values and (b) k values of glass substrate and single-layer $\mathrm{MgF}_{2}$ and $\mathrm{Nb}_{2} \mathrm{O}_{5}$ films; (c) and (d) $\mathrm{K}$ values of single-layer $\mathrm{MgF}_{2}$ and $\mathrm{Nb}_{2} \mathrm{O}_{5}$ films compared with Cauchy equation.

After the thicknesses of the $\mathrm{MgF}_{2}$ and $\mathrm{Nb}_{2} \mathrm{O}_{5}$ films matched for the $\lambda / 4$ condition were found, the $\mathrm{MgF}_{2}-\mathrm{Nb}_{2} \mathrm{O}_{5}$ bilayer films with the periods of two, four, and six were deposited using the e-beam process. The surface morphologies in Figure 4 compares the surface morphologies of the bilayer films. These FESEM images show that when the deposition was done at room temperature, a dense surface morphology was presented on the surfaces of $\mathrm{Nb}_{2} \mathrm{O}_{5}$ films, consisting of growing nanocrystalline particles, which were polycrystalline materials with a grain size of only a few nanometers. Although nanocrystalline particles were observed, the XRD patterns indicated that the $\mathrm{MgF}_{2}$ and $\mathrm{Nb}_{2} \mathrm{O}_{5}$ singlelayer films and the $\mathrm{MgF}_{2}-\mathrm{Nb}_{2} \mathrm{O}_{5}$ bilayer films presented amorphous structures. The results in Figure 4 also show that the nanocrystalline $\mathrm{Nb}_{2} \mathrm{O}_{5}$ grains presented the uniform particle sizes. The average crystallite sizes were 12.3, 16.7, and 22.1nm for two (Figure 4(a)), four (Figure 4(b)), and six (Figure 4(c)) periods.
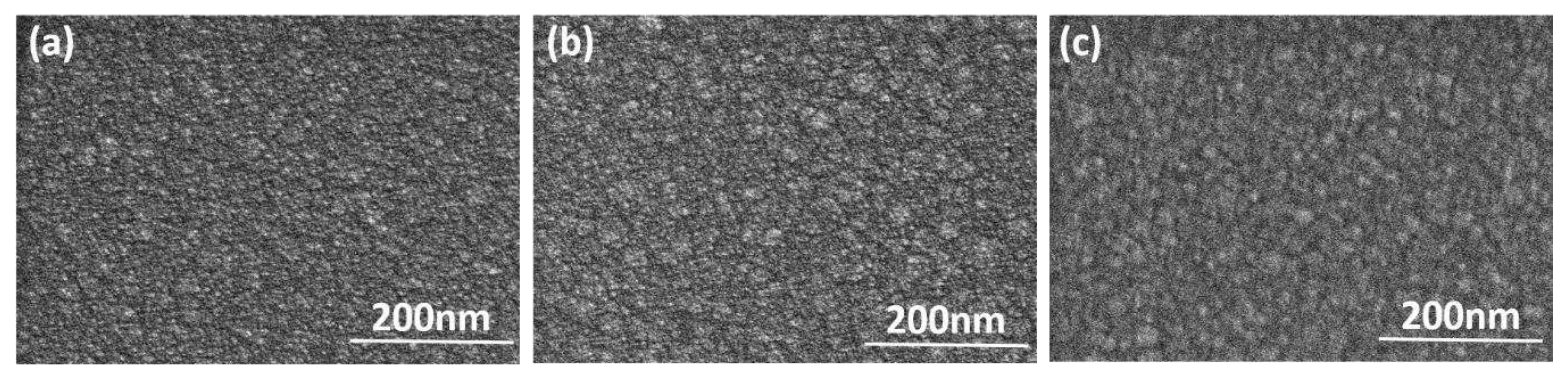

Figure 4. Surface morphologies of $\mathrm{MgF}_{2}-\mathrm{Nb}_{2} \mathrm{O}_{5}$ bilayer films with (a) two, (b) four, and (c) six periods. 
An AFM with a tapping mode could be used to analyze the surfaces' roughness of the $\mathrm{Nb}_{2} \mathrm{O}_{5}$ films on top of the $\mathrm{MgF}_{2}-\mathrm{Nb}_{2} \mathrm{O}_{5}$ bilayer films with different period numbers. Because we deposited the $\mathrm{MgF}_{2}-\mathrm{Nb}_{2} \mathrm{O}_{5}$ bilayer films at room temperature, we believed they would have a lower activation energy, and the $\mathrm{Nb}_{2} \mathrm{O}_{5}$ films would have smaller particle sizes and less roughness. As two, four, and six periods were deposited, as Figure 5 shows, their average roughness (Sa) was 1.21, 1.28, and $1.35 \mathrm{~nm}$ and their root-mean-square (rms, Sq) surface roughness of the $\mathrm{Nb}_{2} \mathrm{O}_{5}$ films was $1.56,1.68$, and $1.75 \mathrm{~nm}$. These results mean that the roughness of the $\mathrm{Nb}_{2} \mathrm{O}_{5}$ films on four- and six-period bilayers was greater than on two periods. The results also prove that all the $\mathrm{Nb}_{2} \mathrm{O}_{5}$ films' surfaces were relatively smooth, but their roughness slightly increased with the period number.

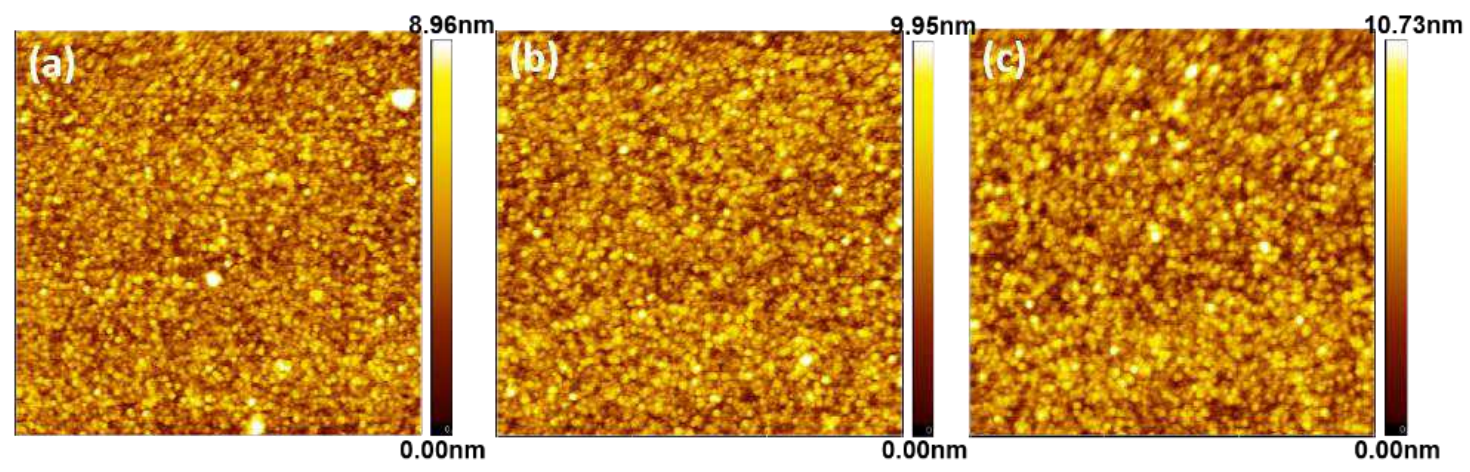

Figure 5. Roughness analysis of $\mathrm{MgF}_{2}-\mathrm{Nb}_{2} \mathrm{O}_{5}$ bilayer films with (a) two, (b) four, and (c) six periods.

Because we wanted to fabricate a DBR for reflecting the blue light and with a central wavelength of $450 \mathrm{~nm}$, the $n$ values of 1.29 and 2.29 were incorporated into the equation $d=\lambda /(4 \mathrm{n})$ to determine the thicknesses (d) of the single-layer $\mathrm{MgF}_{2}$ and $\mathrm{Nb}_{2} \mathrm{O}_{5}$ films. The calculated thicknesses of the $\mathrm{MgF}_{2}$ and $\mathrm{Nb}_{2} \mathrm{O}_{5}$ films for each period were 80.9 and $49.0 \mathrm{~nm}$, and the calculated total thicknesses of the $\mathrm{MgF}_{2}-\mathrm{Nb}_{2} \mathrm{O}_{5}$ bilayer films with two, four, and six periods were 259.8, 519.6, and 779.4nm. FESEM cross-sectional images of the DRBs with different periods are shown in Figure 6, where the entire multilayer structure can be seen. The total thicknesses of the deposited $\mathrm{MgF}_{2}-\mathrm{Nb}_{2} \mathrm{O}_{5}$ bilayer films with two, four, and six periods were $242.8,520.0$, and $780.5 \mathrm{~nm}$. The average thicknesses of the $\mathrm{MgF}_{2}$ films for two, four, and six periods were 76.7 (75.3-78.1), 81.0 (80.3-81.5), and 81.3nm (80.2-82.2), 
and those of the $\mathrm{Nb}_{2} \mathrm{O}_{5}$ films were 44.6 (44.0-45.2), 49.0 (48.4-49.7), and 48.8nm (48.4-49.4).

The thicknesses of the individual $\mathrm{MgF}_{2}$ and $\mathrm{Nb}_{2} \mathrm{O}_{5}$ films in Figure 6 have only minor deviations and are in agreement the thicknesses with the target values of $d=80.9$ and $49.0 \mathrm{~nm}$, as obtained from the theoretical calculations using $d=\lambda /(4 n)$. These cross-sectional images show that no voids were formed in the $\mathrm{MgF}_{2}-\mathrm{Nb}_{2} \mathrm{O}_{5}$ bilayer films, and no boundary defects or grain growth could be found at the interfaces of each $\mathrm{MgF}_{2}$ and $\mathrm{Nb}_{2} \mathrm{O}_{5}$ films. Because no small particles or voids were formed and no boundary defects or grain growth were generated at the interfaces of each $\mathrm{MgF}_{2}$ and $\mathrm{Nb}_{2} \mathrm{O}_{5}$ films, we were able to disregard Mie and Rayleigh scatterings ${ }^{21}$ and identify the $\mathrm{MgF}_{2}-\mathrm{Nb}_{2} \mathrm{O}_{5}$ bilayer films with different periods as homogeneous films with uniform $\mathrm{n}$ values.

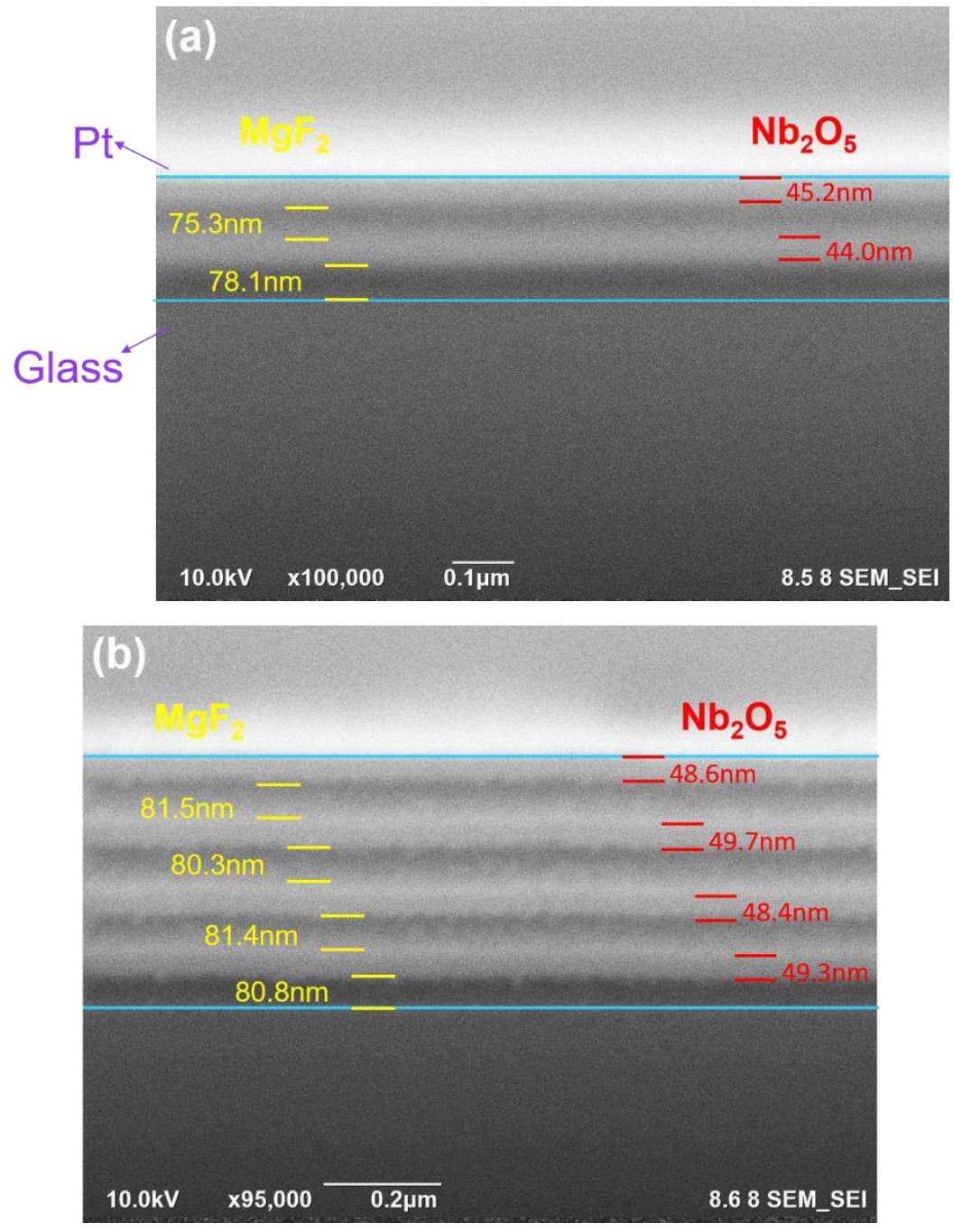




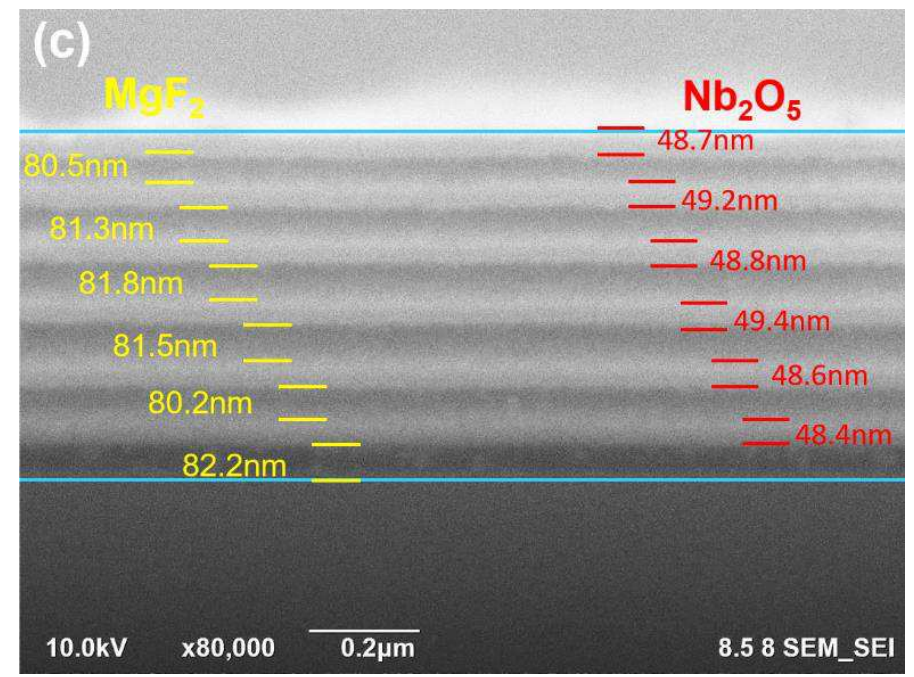

Figure 6. Cross-sectional observations of $\mathrm{MgF}_{2}-\mathrm{Nb}_{2} \mathrm{O}_{5}$ bilayer films with (a) two, (b) four, and (c) six periods.

To further confirm the compositions of each $\mathrm{MgF}_{2}$ and $\mathrm{Nb}_{2} \mathrm{O}_{5}$ layers, we used energy-dispersive X-ray (EDX) to perform the analyses on the cross-sectional structures. EDX analyses proved the presence of elemental $\mathrm{Mg}$ and $\mathrm{F}$ within the $\mathrm{MgF}_{2}$ layer and elemental $\mathrm{Nb}$ within the $\mathrm{Nb}_{2} \mathrm{O}_{5}$ layer. Figure 7 shows the dispersions of the elements in each $\mathrm{MgF}_{2}$ and $\mathrm{Nb}_{2} \mathrm{O}_{5}$ layers using the EDX mapping analysis. The dispersions confirm that the multilayer films were indeed composed of $\mathrm{MgF}_{2}$ and $\mathrm{Nb}_{2} \mathrm{O}_{5}$, and good separation between each $\mathrm{MgF}_{2}$ and $\mathrm{Nb}_{2} \mathrm{O}_{5}$ layers were also really observed. The elemental ratios for $\mathrm{Mg}, \mathrm{F}, \mathrm{Nb}$, and $\mathrm{O}$ were analyzed using FESEM equipped with $\mathrm{EDX}$, and the average atomic ratio of $\mathrm{Mg}$ to $\mathrm{F}$ was $2.00( \pm 0.015): 1$ and that of $\mathrm{Nb}$ to $\mathrm{O}$ was $2.51( \pm 0.018): 1$. Another important reason affecting the reflective properties was that the $\mathrm{MgF}_{2}$ and $\mathrm{Nb}_{2} \mathrm{O}_{5}$ films formed compositions when the $\mathrm{MgF}_{2}$ and $\mathrm{Nb}_{2} \mathrm{O}_{5}$ films were deposited. Because the films were deposited at room temperature, we can observe in the Figure 7 cross-sectional images that there were boundaries in the different $\mathrm{MgF}_{2}$ and $\mathrm{Nb}_{2} \mathrm{O}_{5}$ layers. The properties of central wavelength and reflective ratio in the reflective spectra matched those of the simulation results, indicating a reaction between the $\mathrm{MgF}_{2}$ and $\mathrm{Nb}_{2} \mathrm{O}_{5}$ films did not happen. 


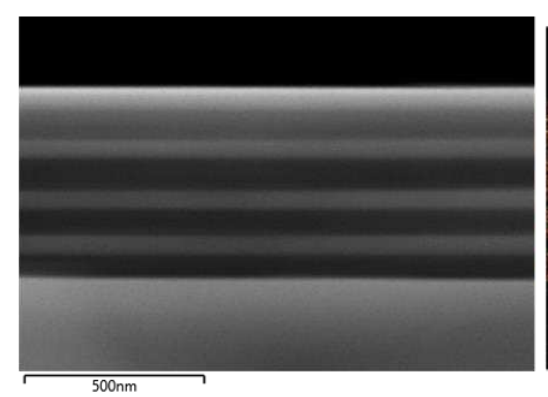

$\mathrm{Nb} \mathrm{L} \alpha 1$

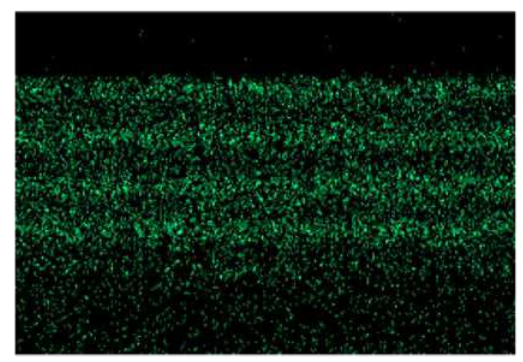

$500 \mathrm{~nm}$

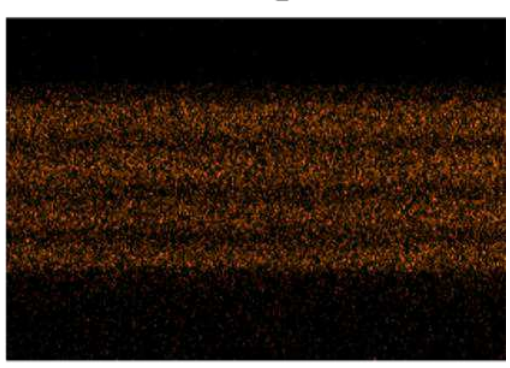

Mg Ka1_2

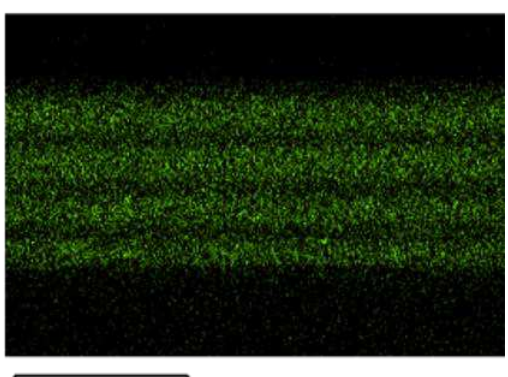

$500 \mathrm{~nm}$

Figure 7. Cross-sectional EDX mapping measurements of four-period $\mathrm{MgF}_{2}-\mathrm{Nb}_{2} \mathrm{O}_{5}$ bilayer films.

After the two, four, and six periods of $\mathrm{MgF}_{2}-\mathrm{Nb}_{2} \mathrm{O}_{5}$ bilayer films were deposited, the optimum reflective ratios of optical spectra were $66.8 \%, 92.5 \%$, and $95.3 \%$ at light wavelengths of $436 \mathrm{~nm}$, 456nm, and 448nm. Using Equation (1), the maximum reflective ratios were calculated to be $70.0 \%$, $95.3 \%$, and $99.3 \%$ when the period numbers of the designed DBRs were two, four, and six. When these simulation results are compared with the measured values, they have no apparent differences in the central light wavelength. The calculated bandwidth for the reflective band of the fabricated DBRs with the $\mathrm{MgF}_{2}-\mathrm{Nb}_{2} \mathrm{O}_{5}$ bilayer films at a specific wavelength $(\lambda)$ can be found using Equation (14) ${ }^{18}$ :

$$
\frac{\Delta \lambda}{\lambda}=(4 / \pi) \arcsin \left[\frac{n_{H}-n_{L}}{n_{H}+n_{L}}\right]
$$

where $n_{L}$ and $n_{H}$ are the $\mathrm{n}$ values of the $\mathrm{MgF}_{2}$ and $\mathrm{Nb}_{2} \mathrm{O}_{5}$ films, $\lambda$ is the central light wavelength for reflectance of the designed DBR, and $\Delta \lambda$ is the reflective bandwidth of DBRs at a specific wavelength. When the measured $n$ values of the $\mathrm{MgF}_{2}\left(\mathrm{n}_{\mathrm{L}}=1.39\right)$ and $\mathrm{Nb}_{2} \mathrm{O}_{5}\left(\mathrm{n}_{\mathrm{H}}=2.29\right)$ films are used in Equation (13) to find the bandwidth at the stop-band of blue light (450nm) for the $\mathrm{MgF}_{2}-\mathrm{Nb}_{2} \mathrm{O}_{5}$ bilayer films, the calculated value is $142 \mathrm{~nm}$, meaning light in the light wavelength of $379-521 \mathrm{~nm}$ can be reflected. The measured reflective bandwidths and simulated reflective bandwidths (using an overall transfer matrix) are defined as that the measured reflective ratio is higher than or equal to $90 \%$ of the measured maximum reflective ratio. Hence, as Figure 8 shows, for the bilayer films with two, four, or six 
periods their measured bandwidths were 88nm (385-497nm), 113nm (409-522nm), and 116nm (395$511 \mathrm{~nm})$. The full width at half maximum (FWHM) values of the reflected bands with two, four, or six periods were $263 \mathrm{~nm}(347-610 \mathrm{~nm}), 186 \mathrm{~nm}(386-572 \mathrm{~nm})$, and $160 \mathrm{~nm}$ (384-544nm). These results prove that the simulated results have matched the measured ones and also prove that differences in thicknesses and the $\mathrm{n}$ values of the $\mathrm{MgF}_{2}$ and $\mathrm{Nb}_{2} \mathrm{O}_{5}$ films are the reasons for the variation in the central light wavelength and the difference in bandwidth.

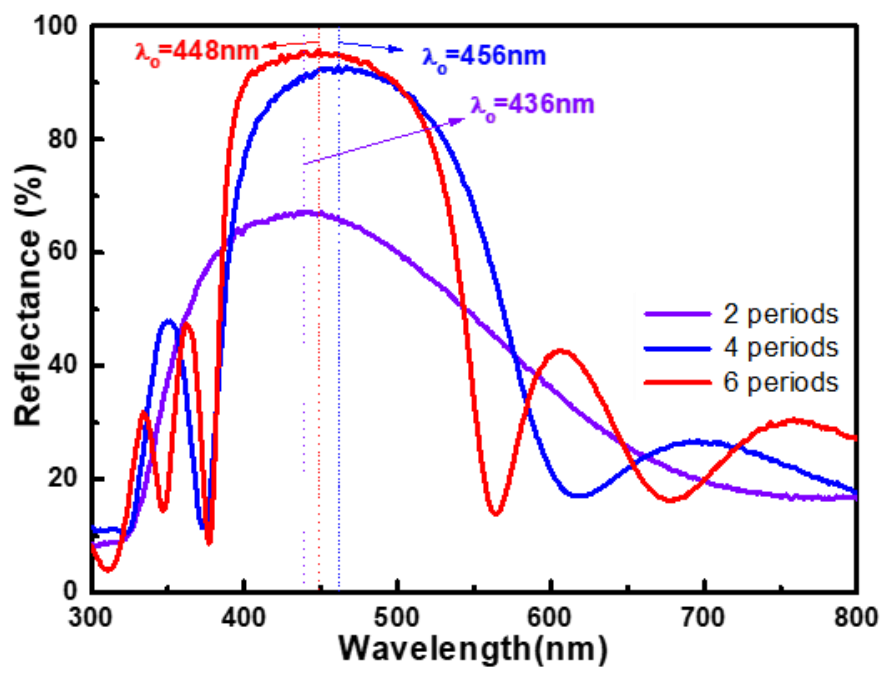

Figure 8. Measured reflectance rates of $\mathrm{MgF}_{2}-\mathrm{Nb}_{2} \mathrm{O}_{5}$ bilayer films as a function of period number.

Figure 9 presents the measured transmittance ratio for the $\mathrm{MgF}_{2}-\mathrm{Nb}_{2} \mathrm{O}_{5}$ bilayer films with different period numbers. Figures 8 and 9 show an important result: when the light wavelengths of transmittance and reflective spectra are longer than $350 \mathrm{~nm}$, the reflective ratio and the transmittance ratio have inverse results, and the addition of both values is almost equal to 1 . 


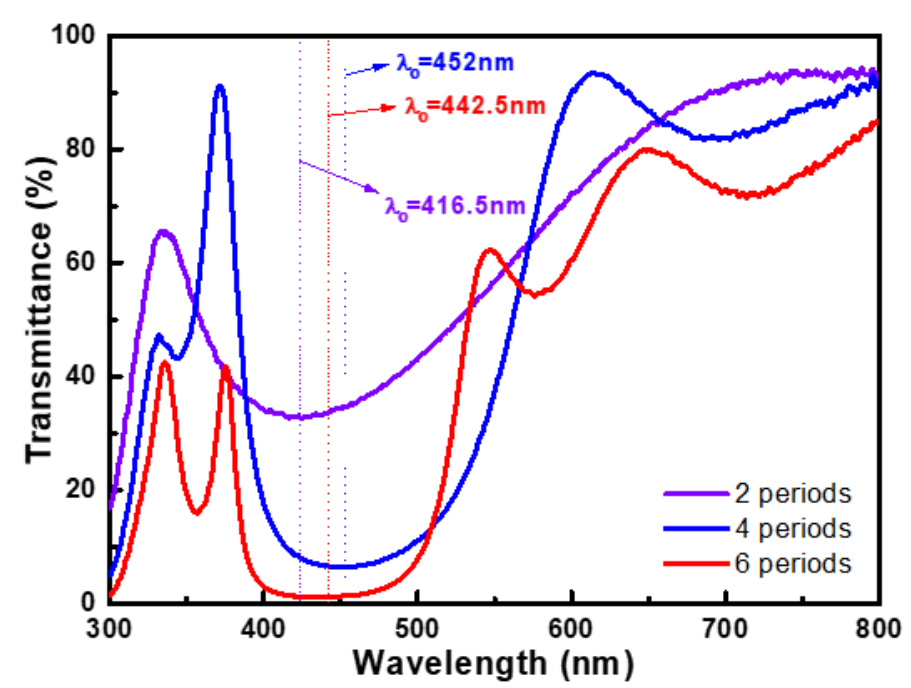

Figure 9. Measured transmittance rate of $\mathrm{MgF}_{2}-\mathrm{Nb}_{2} \mathrm{O}_{5}$ bilayer films with different period numbers.

The reflectance spectra of the experimental measurements and the theoretical calculations of the $\mathrm{MgF}_{2}-\mathrm{Nb}_{2} \mathrm{O}_{5}$ bilayer films in the light wavelength of $300-800 \mathrm{~nm}$ are compared in Figure 10 . The theoretical results were calculated by incorporating the variable $\mathrm{n}$ values and thicknesses of the $\mathrm{MgF}_{2}$ and $\mathrm{Nb}_{2} \mathrm{O}_{5}$ films into the calculations for the overall transfer matrices (Equations (6)-(9)). As Figure 10 shows, the experimental reflectance spectra were similar to the simulation results in the light wavelength of $300-800 \mathrm{~nm}$, and the measured central wavelengths for the three designed reflectors overlapped with the simulation results. This outcome suggests that the theoretically calculated spectra have good agreement with the experimentally measured results when we used the variable thicknesses of each layer and the variable $\mathrm{n}$ values of each wavelength for the whole $\mathrm{MgF}_{2}-\mathrm{Nb}_{2} \mathrm{O}_{5}$ bilayer films. Figure 10 indicates that when the wavelength was larger than $500 \mathrm{~nm}$, moderate deviations in the reflective spectra were observed for the $\mathrm{MgF}_{2}-\mathrm{Nb}_{2} \mathrm{O}_{5}$ bilayer films with different periods.

Many reasons can cause the designed DBRs with different-period $\mathrm{MgF}_{2}-\mathrm{Nb}_{2} \mathrm{O}_{5}$ bilayer films having the deviations in their central light wavelengths. The two main theorems could have been variations in the thicknesses of the $\mathrm{MgF}_{2}-\mathrm{Nb}_{2} \mathrm{O}_{5}$ bilayer films and decreases in the $\mathrm{n}$ values of the $\mathrm{MgF}_{2}$ and $\mathrm{Nb}_{2} \mathrm{O}_{5}$ films as the light wavelength increased. We believe that differences in the individual and total thicknesses of the multilayer $\mathrm{MgF}_{2}-\mathrm{Nb}_{2} \mathrm{O}_{5}$ films caused the small differences between the simulated (obtained from $\mathrm{d}=\lambda /(4 \mathrm{n})$ ) and reflective central wavelengths and reflectance bandwidths. The FESEM images in Figure 6 were used to measure the thicknesses of the $\mathrm{MgF}_{2}$ and $\mathrm{Nb}_{2} \mathrm{O}_{5}$ films 
in each layers, and the average thicknesses of the $\mathrm{MgF}_{2}$ and $\mathrm{Nb}_{2} \mathrm{O}_{5}$ films for the deposited DBRs with two periods were 76.7 and $44.6 \mathrm{~nm}$. As using the equation of $d=\lambda /(4 \mathrm{n})$, the central light wavelengths determined from the $\mathrm{MgF}_{2}$ and $\mathrm{Nb}_{2} \mathrm{O}_{5}$ films having the thicknesses of 76.7 and $44.6 \mathrm{~nm}$ were 427 and $410 \mathrm{~nm}$. Although the two values are close to the measured and simulated results of 439 and $434 \mathrm{~nm}$, they still caused deviations in the central wavelengths because of the deviations in the films' thicknesses.

The thicknesses of each of the $\mathrm{MgF}_{2}$ and $\mathrm{Nb}_{2} \mathrm{O}_{5}$ films in the fabricated DBRs with four and six periods were also measured, their average thicknesses in the bilayer films with four periods were 81.0 and $49.0 \mathrm{~nm}$, and with six periods were 81.15 and $48.85 \mathrm{~nm}$. From the equation of $d=\lambda /(4 \mathrm{n})$, the central light wavelengths for the $\mathrm{MgF}_{2}$ and $\mathrm{Nb}_{2} \mathrm{O}_{5}$ films with thicknesses of 81.0 and $49.0 \mathrm{~nm}$ were 450 and $450 \mathrm{~nm}$, and for the $\mathrm{MgF}_{2}$ and $\mathrm{Nb}_{2} \mathrm{O}_{5}$ films with thicknesses of 81.15 and $48.85 \mathrm{~nm}$ their respectively central light wavelengths were 451 and $449 \mathrm{~nm}$. These values were close to the measured and simulated results of 456 and $448 \mathrm{~nm}$ for four periods and of 459 and $439 \mathrm{~nm}$ for six periods. As Figure 6 shows, the thicknesses of the individual $\mathrm{MgF}_{2}$ and $\mathrm{Nb}_{2} \mathrm{O}_{5}$ films in different periods were different, so their central light wavelengths for each layer were also different. We believe that deviations in the thicknesses of the fabricated DBRs are the main reason for the shift in their central light wavelengths, and the results obtained from the simulation of the investigated overall transfer matrix prove this to be the case. As the periods of the bilayer films were two, four, and six, their simulated bandwidths were $103 \mathrm{~nm}(390-493 \mathrm{~nm}), 140 \mathrm{~nm}(400-540 \mathrm{~nm})$, and $104 \mathrm{~nm}(398-502 \mathrm{~nm})$. However, the bandwidths for these bilayer films with the same periods and simulated with an overall transfer matrix matched the measured results. 

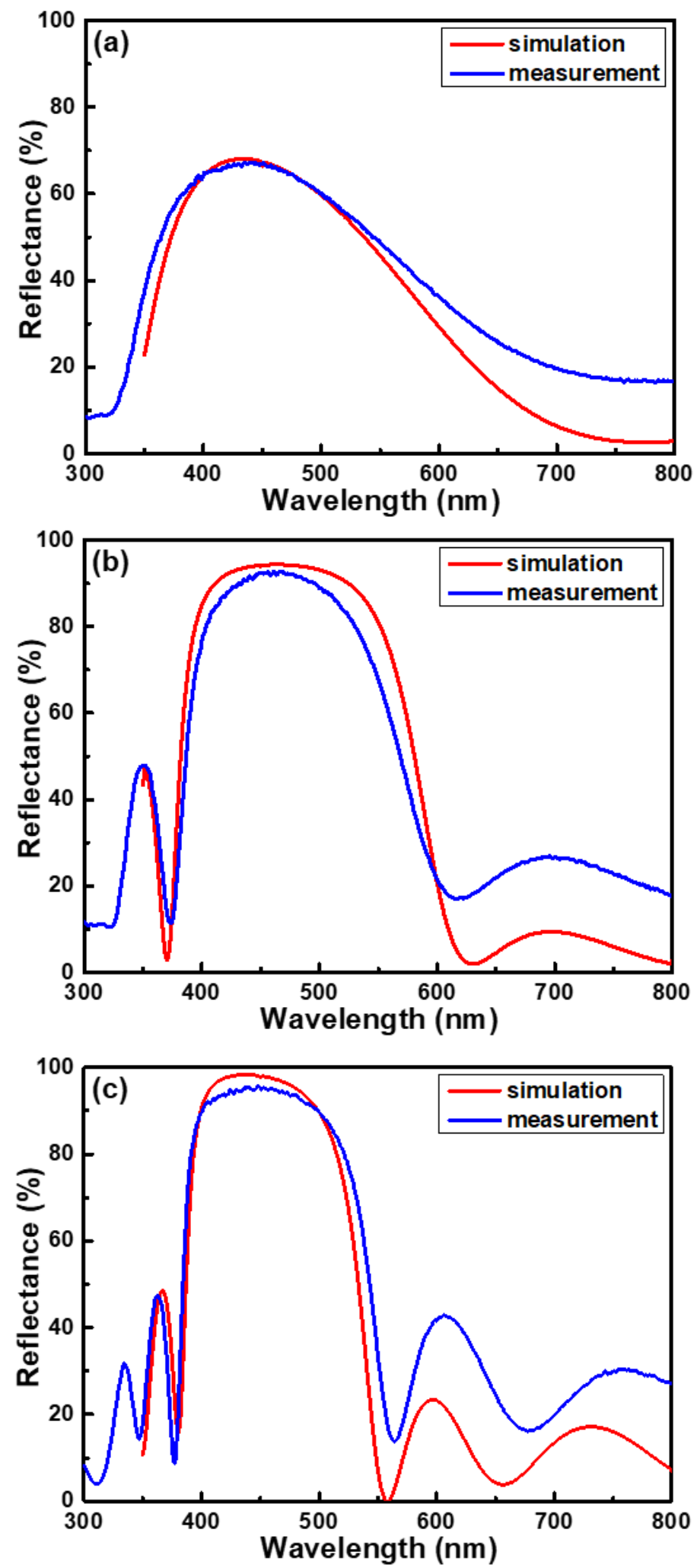

Figure 10. Simulated and measured reflectance spectra of DBRs designed using the $\mathrm{MgF}_{2}-\mathrm{Nb}_{2} \mathrm{O}_{5}$ bilayer films: (a) two, (b) four, and (c) six periods.

Figure 11 compares the maximum reflective ratios using the two simulation methods, and the measured results for the fabricated DBRs with different periods. As the periods for the DBRs of 
$\mathrm{MgF}_{2}-\mathrm{Nb}_{2} \mathrm{O}_{5}$ bilayer films were with two, four, and six, the reflective ratios for a central wavelength of $450 \mathrm{~nm}$ and calculated using Sheppard's equation were $70.0 \%, 95.3 \%$, and $99.3 \%$. When the investigated overall transfer matrix was used to calculate the designed DBRs by the incorporations of $\mathrm{n}$ values and thicknesses, their reflective ratios were $68.0 \%, 94.3 \%$, and $98.3 \%$ for central wavelengths of 436 (two periods), 456 (four periods), and 448nm (six periods). When the fabricated $\mathrm{MgF}_{2}-\mathrm{Nb}_{2} \mathrm{O}_{5}$-based DBRs were used to measure their reflective ratios, they were $66.8 \%$ (for central wavelength of $436 \mathrm{~nm}), 92.8 \% 456 \mathrm{~nm})$, and $95.3 \%$ (448nm). Regardless of whether the fabricated DBRs had different periods, all the deposited DBRs' reflectivity had good uniformity, the deviations of the maximum reflective ratios between the measured results and the two simulation results could be neglectable.

When light strikes the surface of a film, part of light can be transmitted, part will be reflected, and the remaining part can be absorbed. The first law of thermodynamics defines that the sum of the transmitted, reflected, and absorbed radiation energies is equal to the energy of incident light. In other words, the relationships between absorptivity $(\alpha)$, reflectivity $(\eta)$, and transmissivity $(\tau)$ are:

$$
\alpha+\eta+\tau=1
$$

In the past, Liu et al. used lossless $\mathrm{Al}_{2} \mathrm{O}_{3}$ and $\mathrm{TiO}_{2}$ films (or $\mathrm{k}$ values close to zero in the visible light range, defined as $\alpha=0$ ) to fabricate DBRs and found that the reflective ratios of the fabricated devices were higher than the simulation results using Sheppard's approximate equation. ${ }^{5}$ For our DBRs fabricated using $\mathrm{MgF}_{2}-\mathrm{Nb}_{2} \mathrm{O}_{5}$ bilayer films, maximum $\alpha$ plus maximum $\tau$ was smaller than 1 . From the measurements of the transmission and reflection ratios, we can quantify that the total scattering and absorption losses at $450 \mathrm{~nm}$ are $\alpha=2.2 \%$. These results prove that the higher $\mathrm{k}$ value of the $\mathrm{Nb}_{2} \mathrm{O}_{5}$ film meant the absorptivity $(\alpha)$ was not equal to zero, so the reflective ratios of the $\mathrm{MgF}_{2}-\mathrm{Nb}_{2} \mathrm{O}_{5}$ bilayer films were smaller than those obtained using Sheppard's approximate equation. 


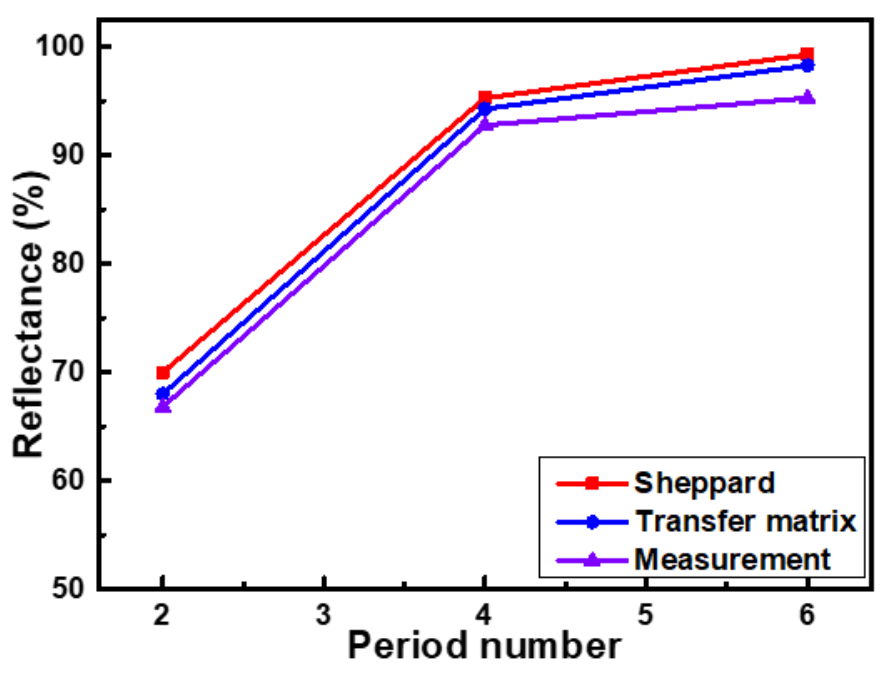

Figure 11. Comparison of maximum reflective ratios using different simulation methods, and measurement results of fabricated DBRs with different periods.

\section{Conclusions}

When $\mathrm{MgF}_{2}-\mathrm{Nb}_{2} \mathrm{O}_{5}$ bilayer films were used to fabricate DBRs with two, four, and six periods, the total thicknesses of the calculated $\mathrm{MgF}_{2}-\mathrm{Nb}_{2} \mathrm{O}_{5}$ bilayer films were 259.8, 519.6, and 779.4nm, and the measured total thicknesses of the deposited $\mathrm{MgF}_{2}-\mathrm{Nb}_{2} \mathrm{O}_{5}$ bilayer films were 242.8, 520.0, and $780.5 \mathrm{~nm}$. When we used two, four, and six as the period numbers to deposit the $\mathrm{MgF}_{2}-\mathrm{Nb}_{2} \mathrm{O}_{5}$ bilayer films, the simulated maximum reflective ratios using Sheppard's approximation equation were 70.0\%, 95.3\%, and 99.3\%; using an overall transfer matrix, the values were $68.0 \%, 94.3 \%$, and $98.3 \%$, and the measured maximum reflective ratios were $66.8 \%$ (at $436 \mathrm{~nm}), 92.8 \%(448 \mathrm{~nm})$, and $95.3 \%$ (456nm). The simulated bandwidth of the designed DBRs with $\mathrm{MgF}_{2}-\mathrm{Nb}_{2} \mathrm{O}_{5}$ bilayer films at $450 \mathrm{~nm}$ was $142 \mathrm{~nm}$. As the designed $\mathrm{MgF}_{2}-\mathrm{Nb}_{2} \mathrm{O}_{5}$ bilayer films were two, four, and six periods, their simulated bandwidths with an overall transfer matrix were $103 \mathrm{~nm}(390-493 \mathrm{~nm}), 140 \mathrm{~nm}(400$ $540 \mathrm{~nm})$, and $104 \mathrm{~nm}(398-502 \mathrm{~nm})$, and the measured bandwidths for the deposited bilayer films were $88 \mathrm{~nm}(385-497 \mathrm{~nm}), 113 \mathrm{~nm}(409-522 \mathrm{~nm})$, and $116 \mathrm{~nm}(395-511 \mathrm{~nm})$. The results in this study prove that the investigated overall transfer matrix can be successfully used as a simulation tool to calculate the reflective spectra of fabricated $\mathrm{MgF}_{2}-\mathrm{Nb}_{2} \mathrm{O}_{5}$ bilayer films. 
Acknowledgments: This work was supported by Ministry of Science and Technology (MOST) projects 109-2221-E-390-023 and MOST 109-2622-E-390-001-CC3.

\section{References}

1. Lee, G. J., Hong, I. Y., Kim, T. K., Park, H. J., Oh, S. K., Cha, Y. J., Park, M. J., Choi, K. J. \& Kwak, J. S. Design of ITO/SiO$/ 2 / \mathrm{TiO}_{2}$ distributed Bragg reflectors as a $p$-type electrode in $\mathrm{GaN}$-based flip-chip light emitting diodes. Appl. Sur. Sci. 477, 220-225 (2019).

2. Lee, Y. S., Moon, J. H., Moon, Y. T., Choi, B. \& Oh, J. T. Using $\mathrm{SiO}_{2}$-Based Distributed Bragg Reflector to Improve the Performance of AlGaInP-Based Red Micro-Light Emitting Diode. ECS J. Solid State Sci. Technol. 9, 036002 (2020).

3. Butt, M. A., Fomchenkov, S. A. \& Khonina, S. N. Multilayer dielectric stack Notch filter for 450$700 \mathrm{~nm}$ wavelength spectrum, 3rd International conference Information Technology and Nanotechnology, ITNT, 2017.

4. Pervak, V., Naumov, S., Tempea, G., Yakovlev, V., Krausz, F. \& Apolonski, A. Synthesis and manufacturing the mirrors for ultrafast optics, Proc. of SPIE Vol. 5963, 59631P, 2005.

5. Liu, J., Lin, C .Y., Tzou, W. C., Hsueh, N. K., Yang, C. F. \& Chen, Y. Reflection of Blue Light Using Bi-Layer $\mathrm{Al}_{2} \mathrm{O}_{3}-\mathrm{TiO}_{2}$ E-Beam Coating Films, Crystal Growth and Design 18, 5426-5433 (2018).

6. Chang, T. H., Lee, T. E., Hsueh, N. K., Lin, C. H. \& Yang, C. F. Investigation of $\mathrm{TiO}_{2}-\mathrm{Al}_{2} \mathrm{O}_{3}$ bilayer films as Bragg reflector of blue light by using electron beam evaporation, Microsystem Technolog. 24, 3941-3948 (2018).

7. Lova, P., Manfredi, G., Boarino, L., Comite, A., Laus, M., Patrini, M., Marabelli, F., Soci, C. \& Comoretto, D. Polymer Distributed Bragg Reflectors for Vapor Sensing. ACS Photonics 2, 537-543 (2015).

8. Guldin, S., Kolle, M., Stefik, M., Langford, R., Eder, D. Wiesner U \& Steiner U. Tunable Mesoporous Bragg Reflectors Based on Block-Copolymer Self-Assembly. Adv. Mater. 23, 36643668 (2011). 
9. Li, S. M., Hu, G. J., Wang, C., Zhao, W. C., Ma, G. H., Chen, X. S., Chu, J. H. \& Dai, N. $\mathrm{PbZr}_{0.4} \mathrm{Ti}_{0.6} \mathrm{O}_{3}$ dielectric reflectors with large photonic band gap and high average optical reflectivity. J. Am. Ceram. Soc. 100, 1275-1279 (2017).

10. Wang, Y., Wei, S., Cicconi, R., Tsuji, Y., Shimizu, M., Shimotsuma, Y., Miura, K., Peng, G. D., Neuville, D. R., Poumellec, B. \& Lancry, M. Femtosecond laser direct writing in $\mathrm{SiO}_{2}-\mathrm{Al}_{2} \mathrm{O}_{3}$ binary glasses and thermal stability of Type II permanent modifications. J. Am. Ceram. Soc. 103, 4286-4294 (2020).

11. Dubey R. S. \& Ganesan, V. Fabrication and characterization of $\mathrm{TiO}_{2} / \mathrm{SiO}_{2}$ based Bragg reflectors for light trapping applications. Results in Physics 7, 2271-2276 (2017).

12. Muallem, M., Palatnik, A., Nessim, G. D. \& Tischler, Y. R. Room Temperature Fabrication of Dielectric Bragg Reflectors Composed of a $\mathrm{CaF}_{2} / \mathrm{ZnS}$ Multilayered Coating. ACS Appl. Mater. Interfaces 7, 474-481 (2015).

13. Willey R. R \& Shakoury R. Stable, durable, low-absorbing, low-scattering $\mathrm{MgF}_{2}$ films without heat or added fluorine, Proc. SPIE 10691, Advances in Optical Thin Films VI, 5 June 2018.

14. Chen, K. N., Hsu, C. M., Liu, J., Liou, Y. C. \& Yang, C F. Investigation of Anti-Reflection $\mathrm{Nb}_{2} \mathrm{O}_{5}$ Thin Films by Sputtering Method under Different Deposition Parameters. Micromachines 7, 151 (2016).

15. Du, Y, Chen, B. S., Lin, J. J. \& Yang, C. F. Fabrication of $500 \mathrm{~nm}$ Distributed Bragg Reflector Using $\mathrm{Nb}_{2} \mathrm{O}_{5}-\mathrm{MgF}_{2}$ Multi-layer Films. Accepted by Modern Physics Letter 2020, in pressed.

16. Sheppard, C. J. R. Approximate calculation of the reflection coefficient from a stratified medium, Pure and Applied Optics. J. Europ. Optical Soc. Part A 4, 665-669 (1995).

17. Woo, S. H., Kim, S. H. \& Hwangbo, C. K. Optical and Structural Properties of $\mathrm{TiO}_{2}$ and $\mathrm{MgF}_{2}$ Thin Films by Plasma Ion-Assisted Deposition. J. Korean Phys. Soc. 45, 99-107 (2004).

18. Chen, Y. C., Yang, C. F. \& Hsueh, E. Y. The Application of AZOY Transparent Conductive Oxide Film in Multi-Film Coated Polycarbonate Optical Glasses. J. Electrochem Soc. 157, H987-H990 (2010).

19. Macleod, H. A. Thin-Film Optical Filters, 2nd ed., McGraw-Hill, New York, 1985. 
20. Jenkins, F. A. \& White, H. E. Fundamentals of Optics, 4th ed., McGraw-Hill, Inc., 1981.

21. Lockwood, D. J. Rayleigh and Mie Scattering, Springer, New York, NY, 2016. 
Figures

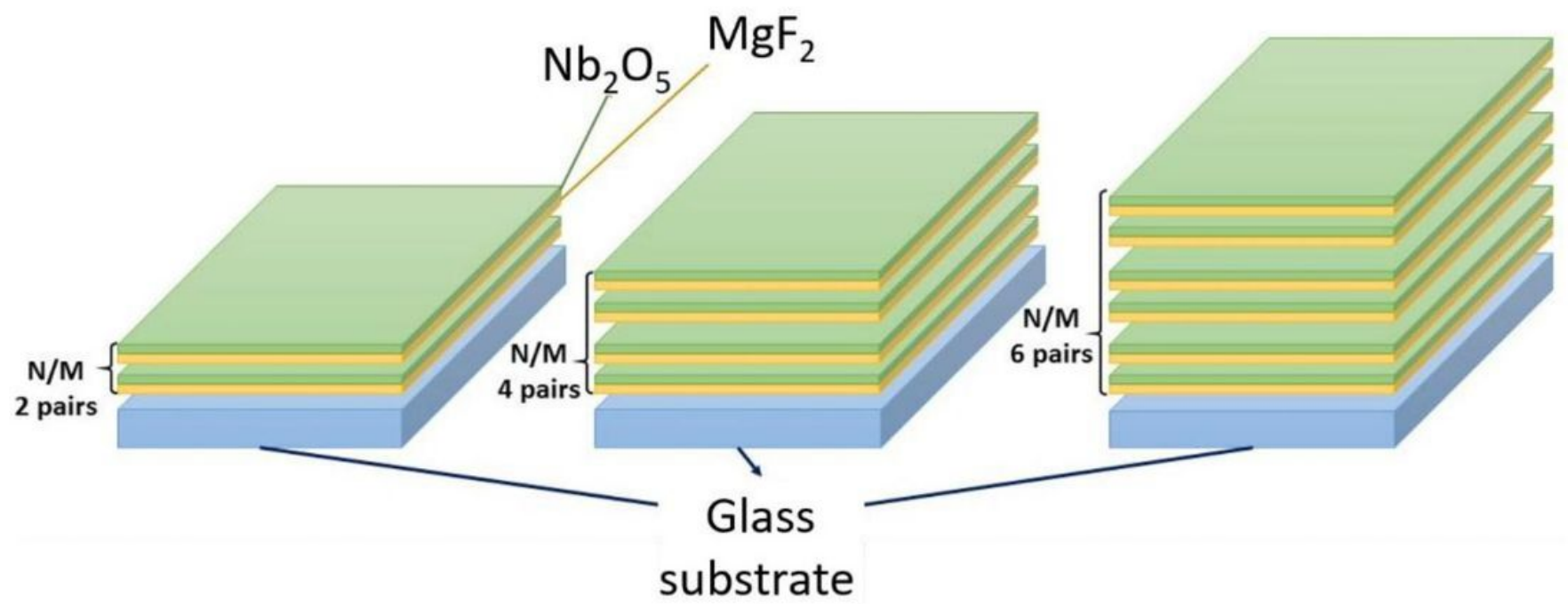

Figure 1

Structure of designed MgF2-Nb205 bilayer films with different periods. 


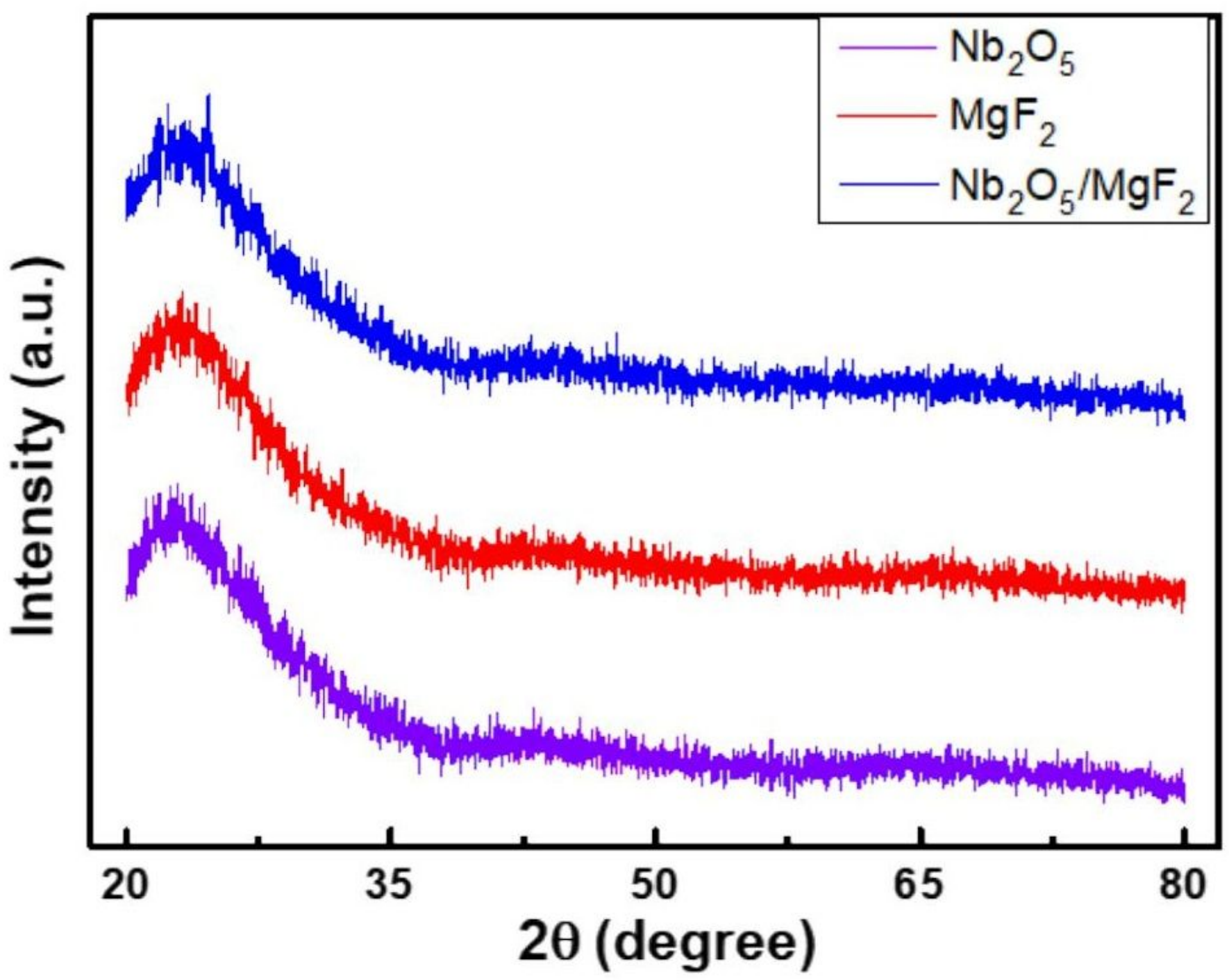

Figure 2

XRD patterns of MgF2 and Nb2O5 single-layer films and MgF2-Nb2O5 bilayer film. 

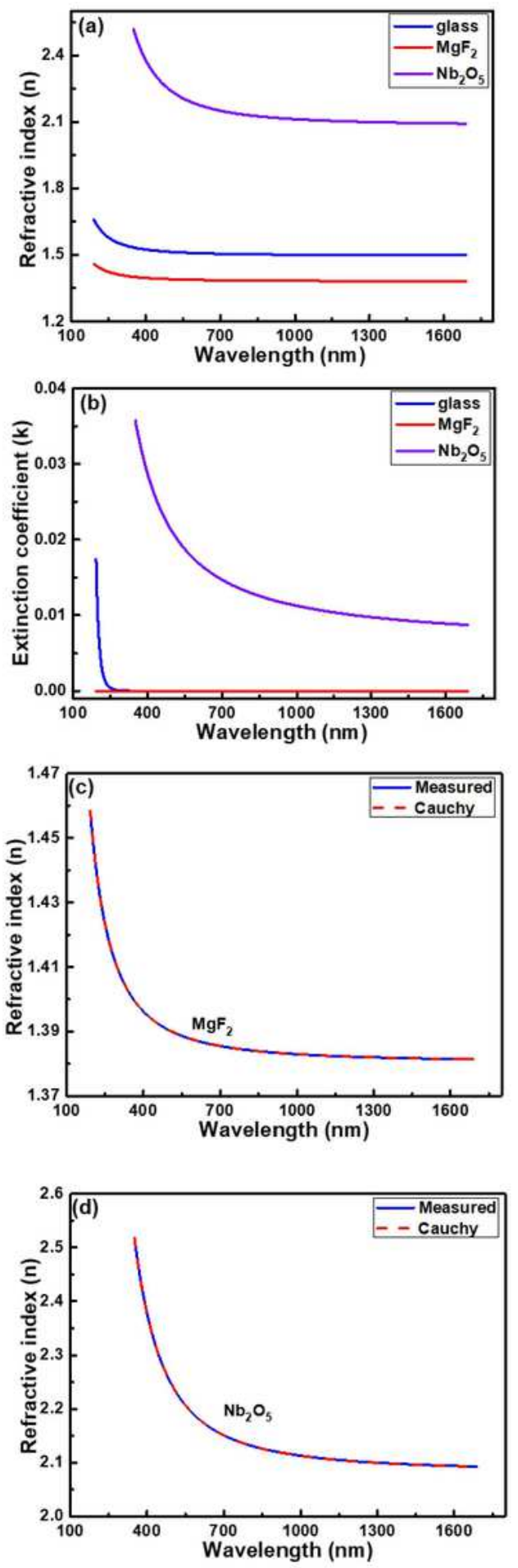

\section{Figure 3}

Measured (a) $n$ values and (b) k values of glass substrate and single-layer MgF2 and Nb205 films; (c) and (d) $\mathrm{K}$ values of single-layer MgF2 and Nb205 films compared with Cauchy equation. 

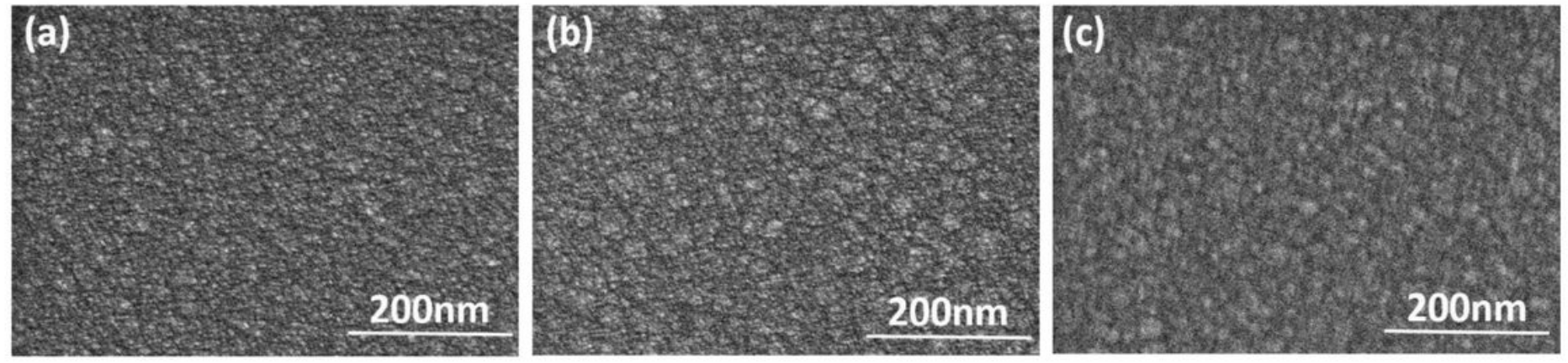

\section{Figure 4}

Surface morphologies of MgF2-Nb205 bilayer films with (a) two, (b) four, and (c) six periods.

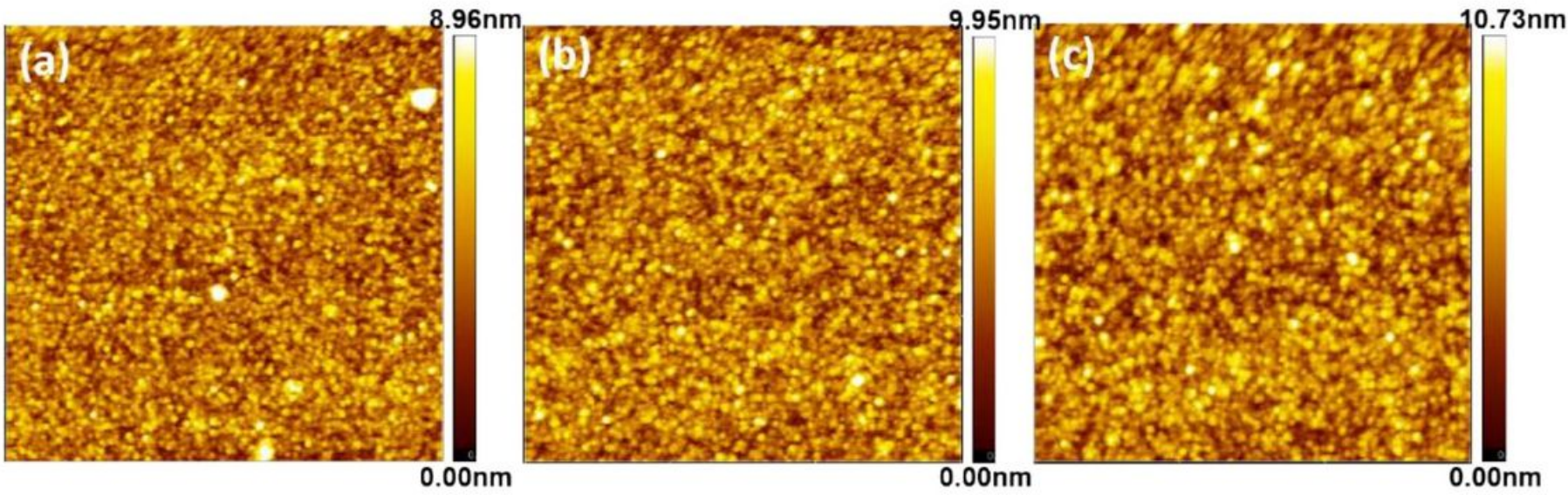

Figure 5

Roughness analysis of MgF2-Nb2O5 bilayer films with (a) two, (b) four, and (c) six periods. 

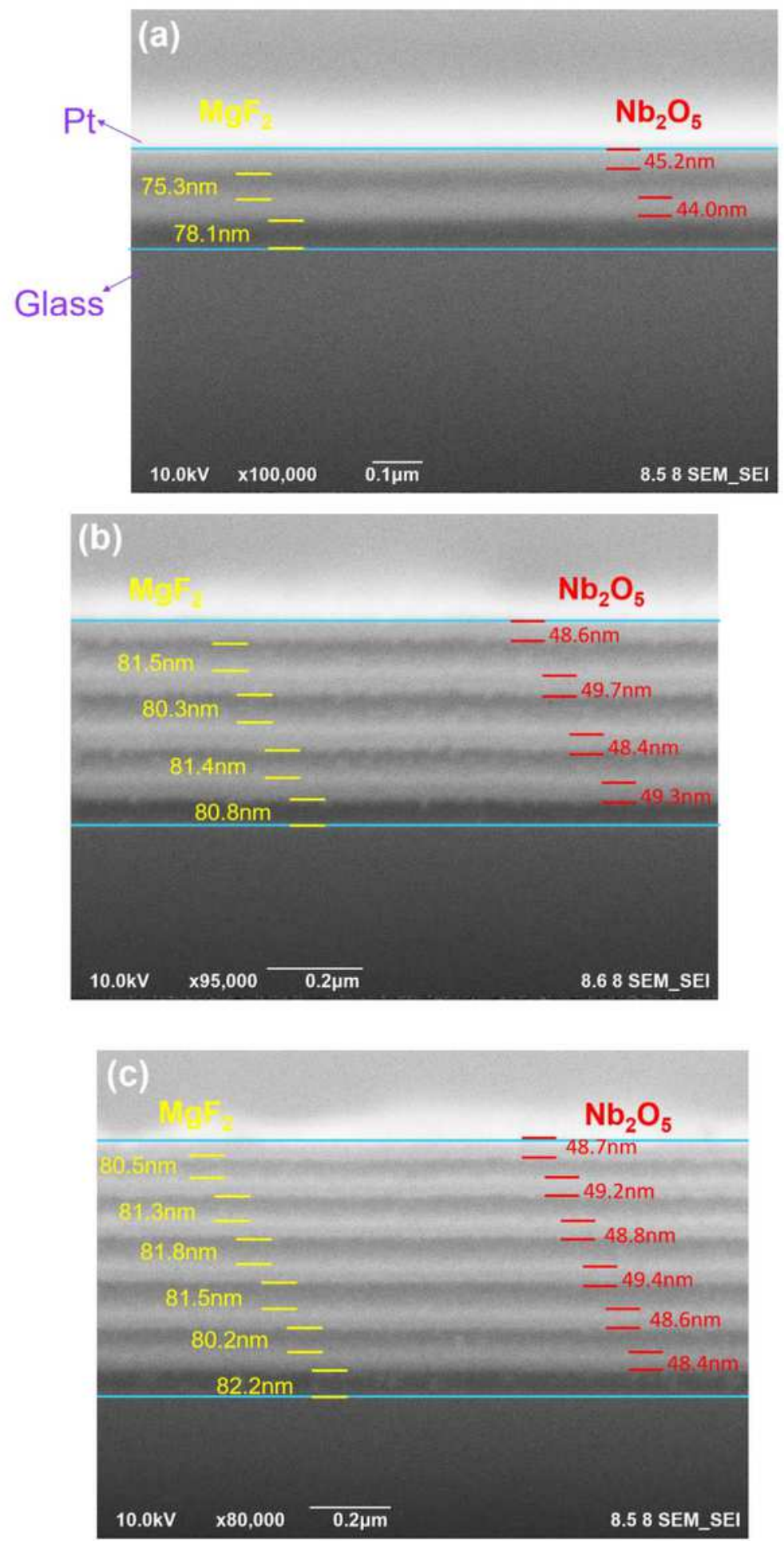

Figure 6

Cross-sectional observations of MgF2-Nb2O5 bilayer films with (a) two, (b) four, and (c) six periods. 


\section{F K 1 1_2}
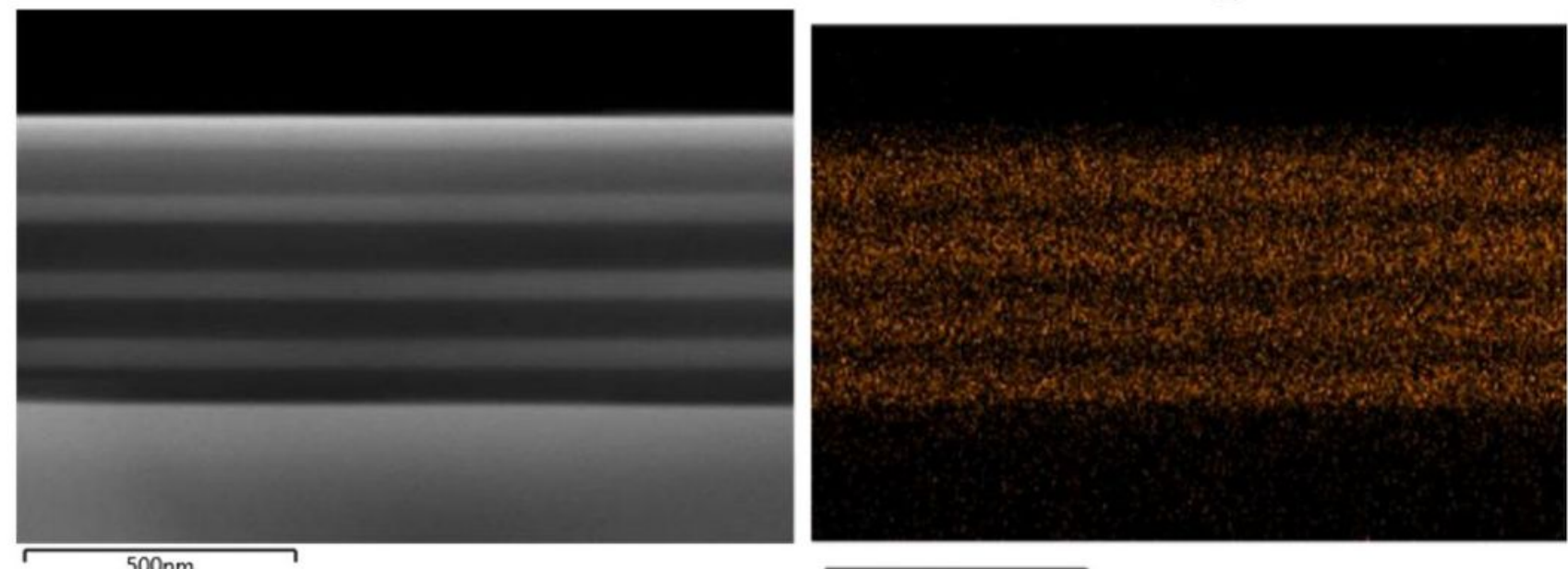

$\mathrm{Nb} \mathrm{L} \alpha 1$

$500 \mathrm{~nm}$

Mg K $\alpha 1 \_2$

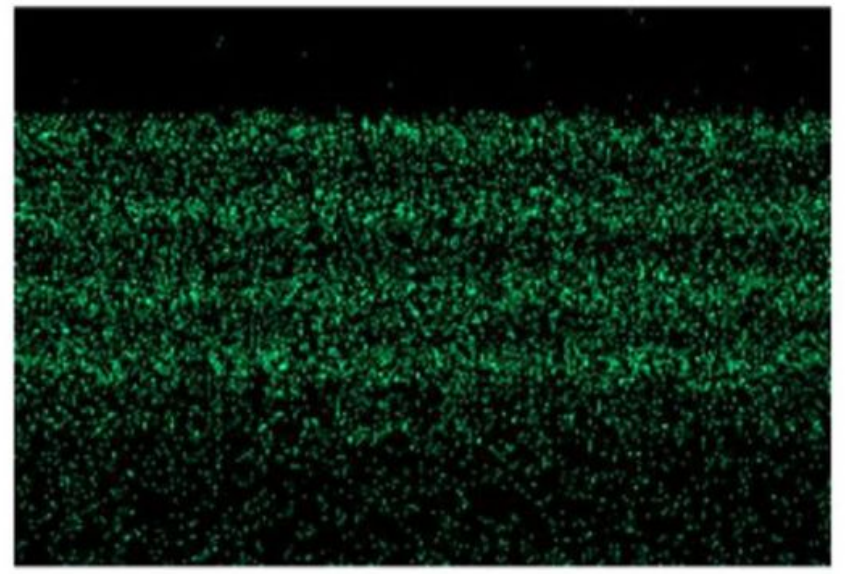

$500 \mathrm{~nm}$

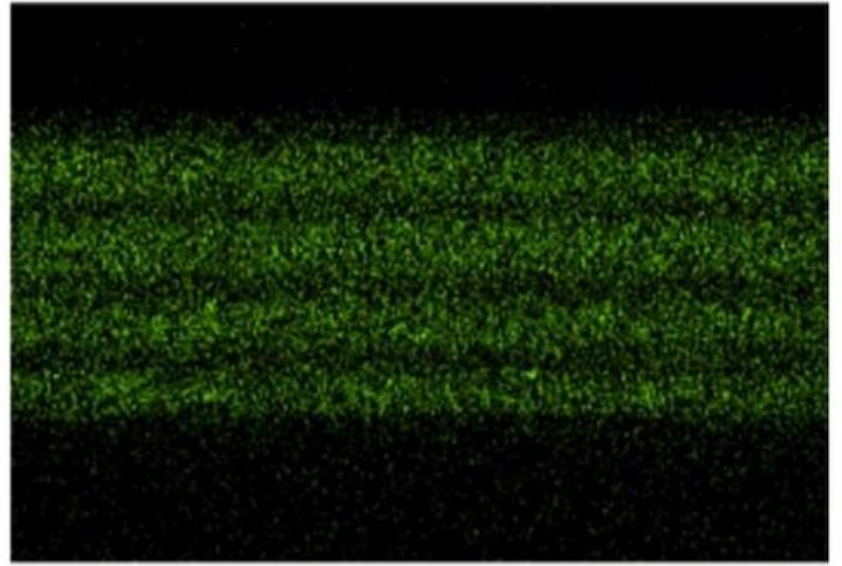

$500 \mathrm{~nm}$

Figure 7

Cross-sectional EDX mapping measurements of four-period MgF2-Nb205 bilayer films. 


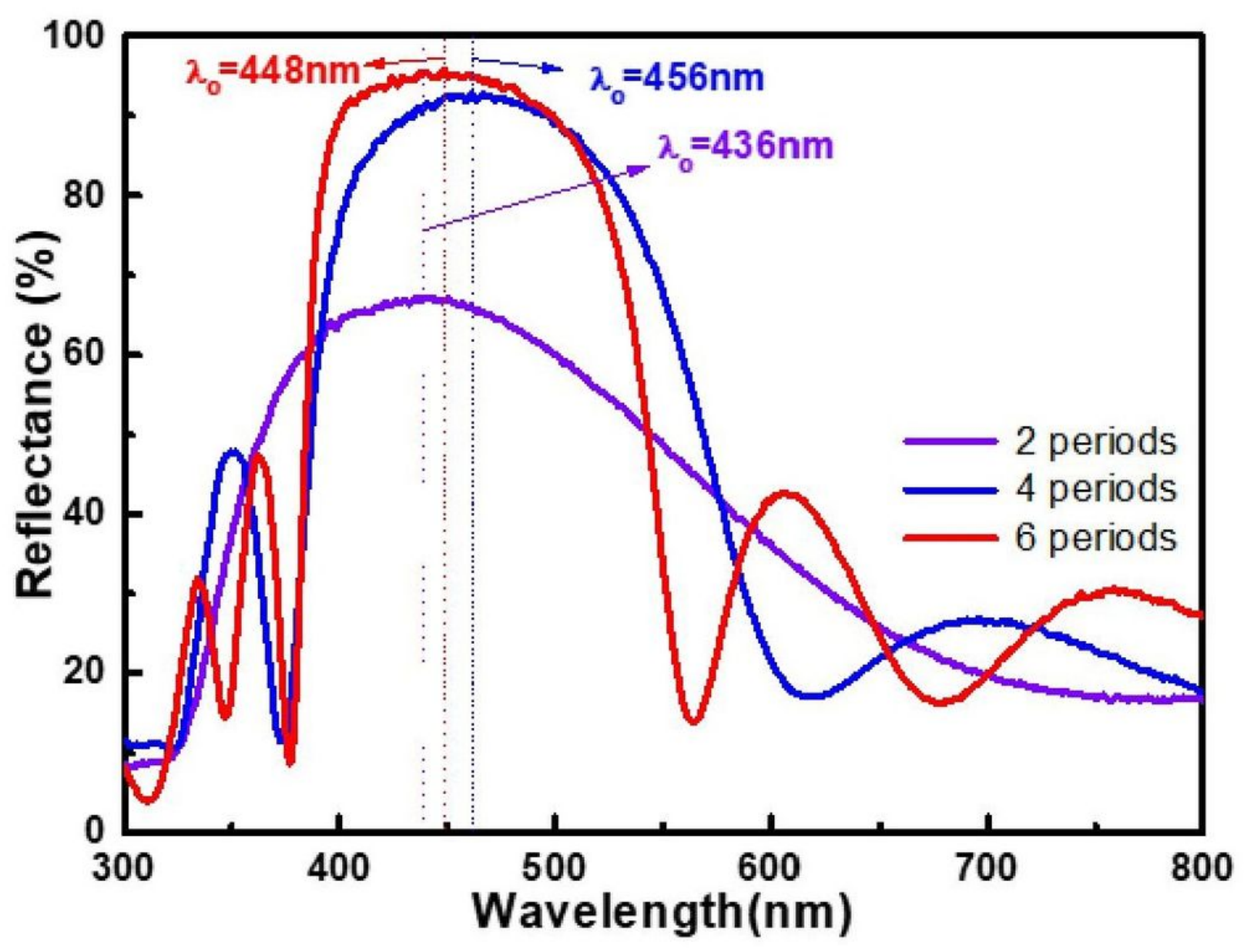

Figure 8

Measured reflectance rates of MgF2-Nb2O5 bilayer films as a function of period number. 


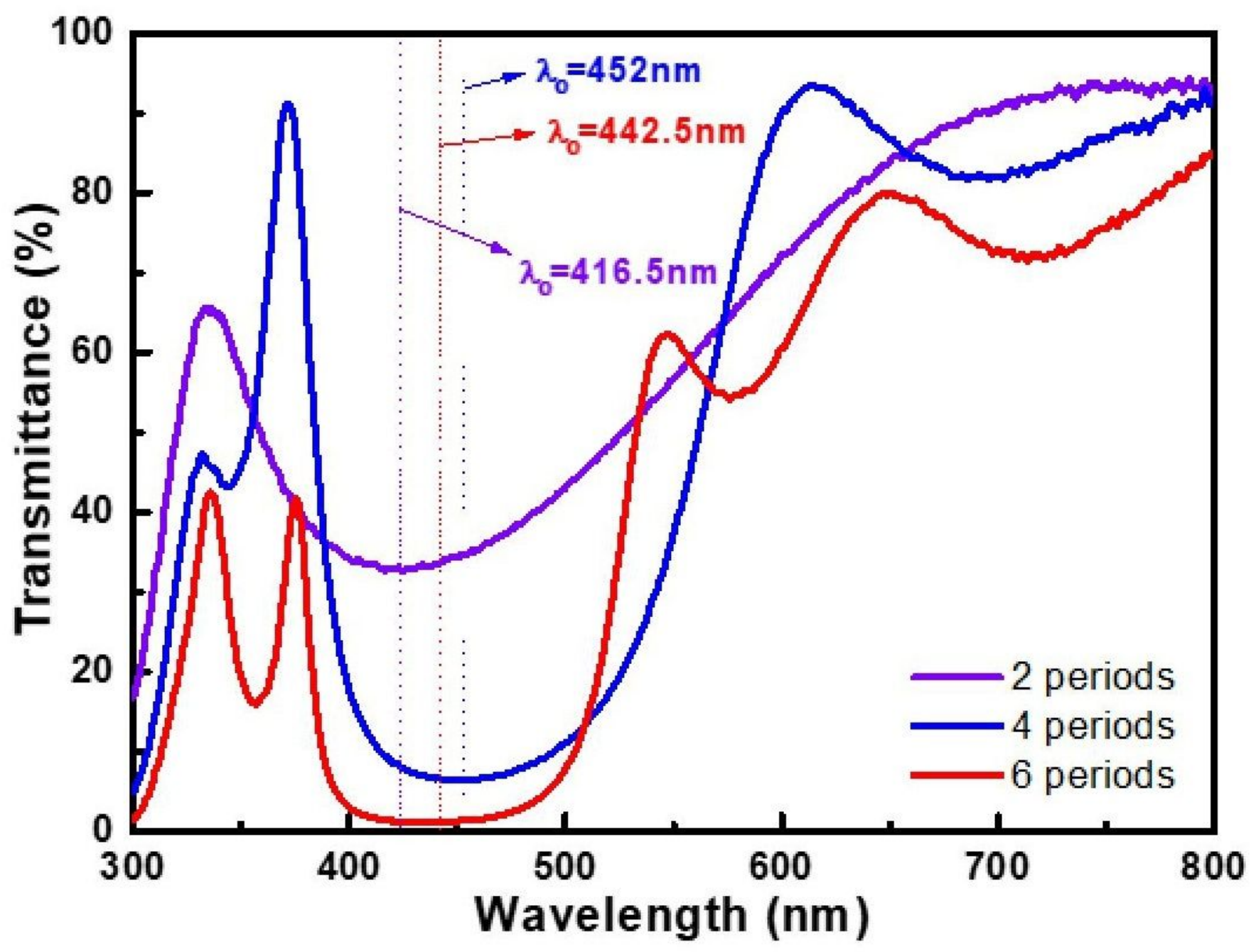

Figure 9

Measured transmittance rate of MgF2-Nb205 bilayer films with different period numbers. 

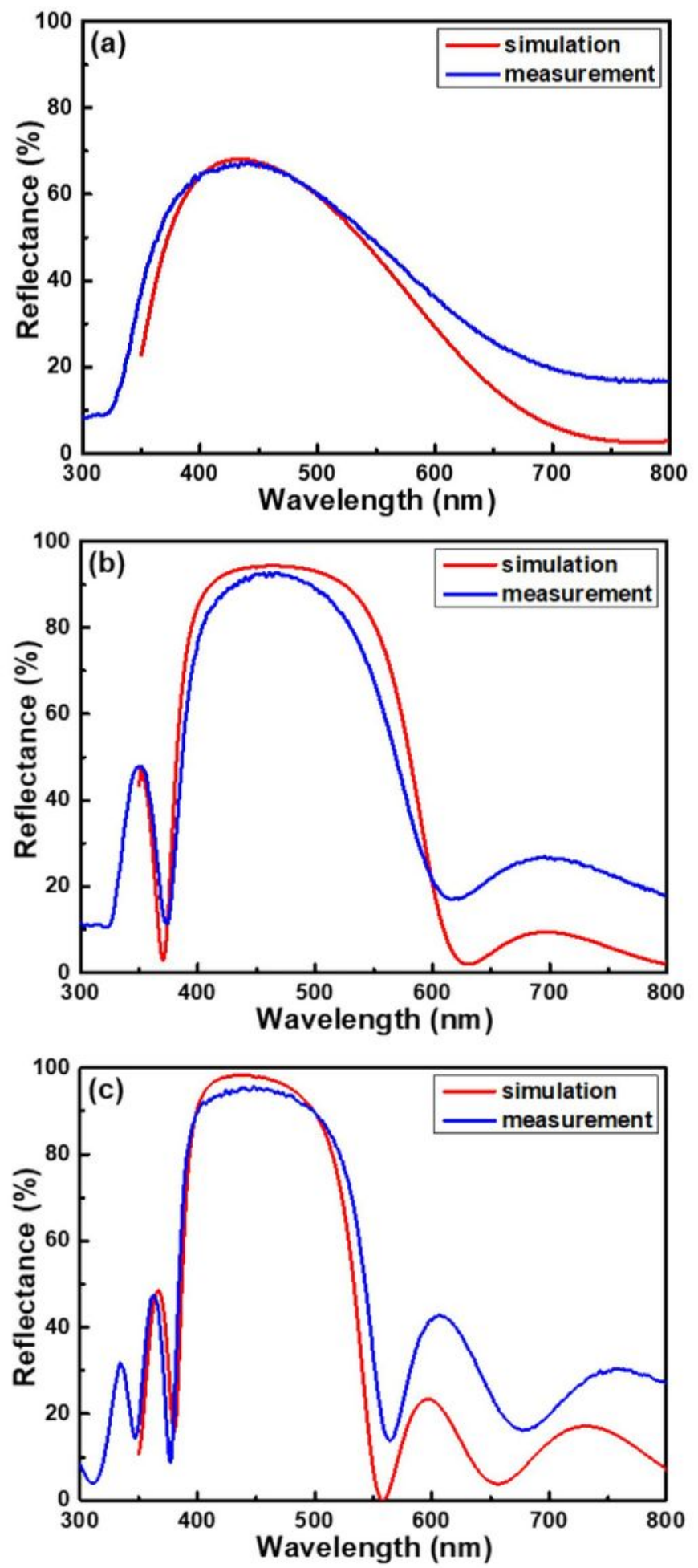

Figure 10

Simulated and measured reflectance spectra of DBRs designed using the MgF2-Nb2O5 bilayer films: (a) two, (b) four, and (c) six periods. 


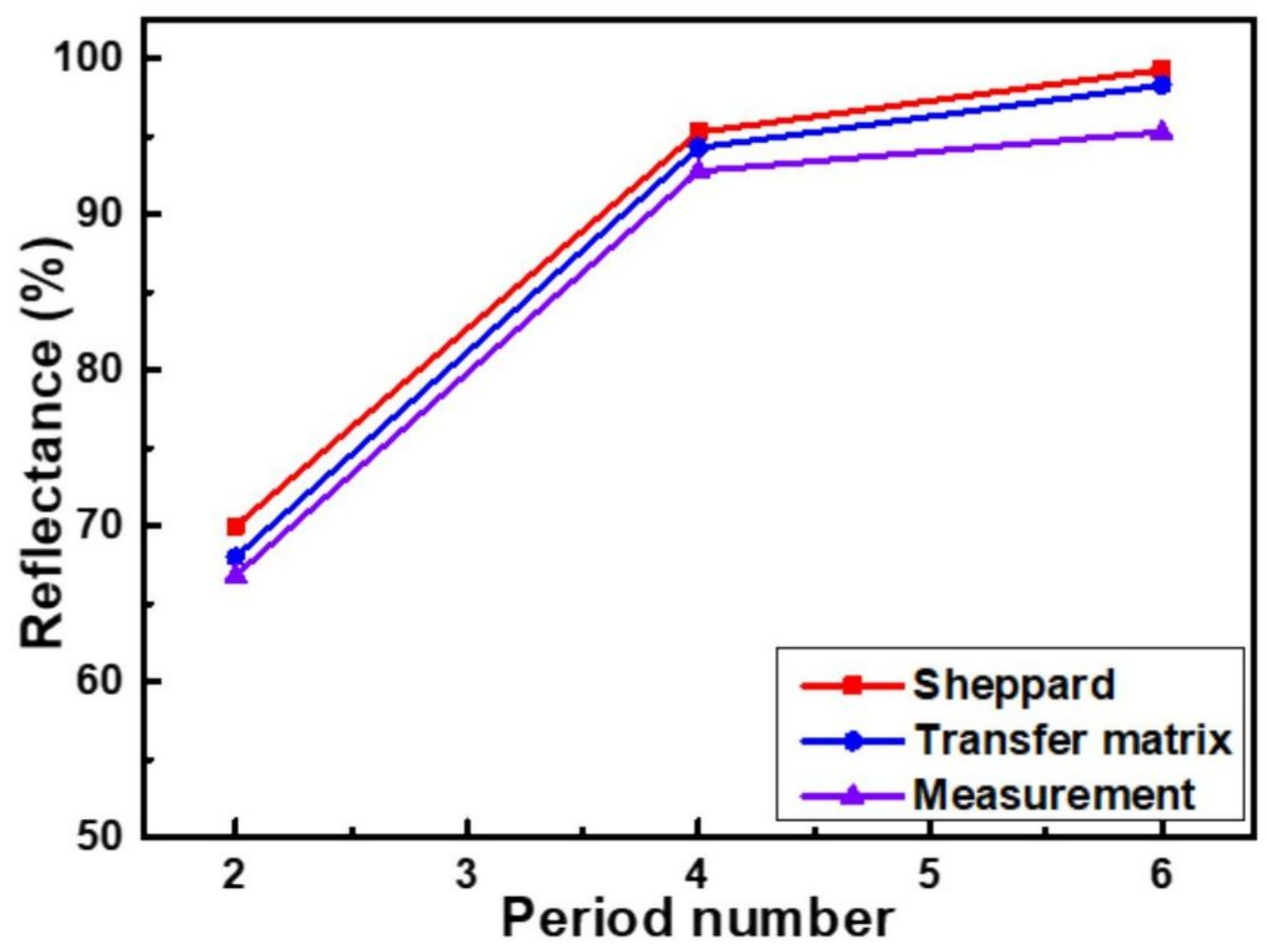

Figure 11

Comparison of maximum reflective ratios using different simulation methods, and measurement results of fabricated DBRs with different periods. 